\title{
Hap-Tech Narration and the Postphenomenological Film
}

\author{
Daniel Paul O'Brien \\ Department of Literature, Film and Theatre Studies, University of Essex, Colchester CO4 3SQ, UK; \\ d.obrien@essex.ac.uk
}

Received: 28 June 2019; Accepted: 8 August 2019; Published: 14 August 2019

\begin{abstract}
Within this paper, I explore the look and feel of the subjective point-of-view (POV) shot in narrative cinema and how it presents an awkward and uncomfortable space for the viewer to inhabit. It considers what David Bordwell has called the surrogate body: the concept in which viewers step into the role of an offscreen protagonist. In numerous films, this style invites the spectator to see and feel through the eyes and movement of a particular type of surrogate character, which as I argue, predominantly consists of killers, victims or socially inept characters. The term I give for this particular trait in cinema is hap-tech narration, which is inspired by Laura Marks' concept of haptic cinema. Unlike Marks' understanding of haptic which focuses upon sensual beauty, hap-tech narration considers phenomenological uncomfortableness which is considered through Don Ihde's philosophy of technology. This paper incorporates Ihde's framework of postphenomenology, which considers how experientiality is changed and filtered through technological devices (which in this analysis will be the technology of the camera and the frame of the screen). Using Ihde's postphenomenological understanding of human-technology relationships (which this work explores in detail), I consider a range of narrative films that utilise POV camerawork, including: Delmer Daves' Dark Passage (1947), Michael Powell's Peeping Tom (1960) and Julian Schnabel's Le Scaphandre et le Papillon (The Diving Bell and Butterfly, 2007). Each of these titles present events through the subjective gaze of a killer, victim or socially damaged character. This paper offers a rationale as to why this is the case by addressing POV through the philosophy of Ihde, enabling an understanding of hap-tech narration to be unpacked, in which viewers are placed into corrupted and damaged corporeality through the technological power of the camera.
\end{abstract}

Keywords: subjective cinema; media; POV; narrative; body; postphenomenology and Ihde

\section{Introduction}

Cinema is a medium that often endeavours to put the spectator in the picture through phenomenological engagement. This essay explores this idea through the movie camera's subjective point-of-view (POV) shot and Don Ihde's concept of postphenomenology, which I use to coin the term "hap-tech narration", which will be explained in due course. Fundamentally, this term incorporates Ihde's philosophy of technology, narrative and phenomenology to put a new slant on cinematic fiction. Cinematic phenomenology has been widely discussed by a range of film theorists, who include Laura U. Marks, Vivian Sobchack, Jennifer Barker, Steven Shaviro, Matilda Mroz, Allan Casebier and Jenny Chamarette, amongst others. Sobchack and Shaviro are pioneers of the film phenomenology discipline, having addressed this topic in the early nineties with their individual books: The Address of the Eye: A Phenomenology of Film Experience [1] and The Cinematic Body [2], respectively. In the former, Sobchack develops the concept of filmic perception as a sensual experience, an idea that is later advanced by Marks in The Skin of the Film: Intercultural Cinema, Embodiment, and the Senses [3], where the author develops her theory of haptic visuality in reference to a collection of sensuous video artworks.

As many of these theorists note, the cinema viewer's relationship with the screen can be a complex one in which they exist in two spaces simultaneously. As Barker [4] notes, when watching a film "[w]e 
exist and move and feel in that space of contact where our surfaces mingle and our musculatures entangle" [4]. As Barker asserts, this phenomenological contact between a viewer's body, screen image and cinematic apparatus can be considered a "transformative space of betweenness" [4].

Within this paper I explore this space through the subjective POV shot, which in a number of films aspires to put the spectator into the surrogate body of an unseen character. Alexander R. Galloway's [5] book, Gaming Essays on Algorithmic Culture, discusses this aesthetic, asserting that "the camera fuses with a character's body, [so that] the viewer sees exactly what the character sees, as if the camera 'eye' were the same as the character ' $\mathrm{I}$ '” [5] (p. 40). Galloway claims that films such as Alfred Hitchcock's Spellbound (1945) [6], Robert Montgomery's Lady in the Lake (1947) [7] and Jonathan Demme's The Silence of the Lambs (1991) [8] (amongst others) are responsible for laying down the foundations of the look and feel of the first-person shooter genre in gaming. Within his specific filmography of titles that incorporate moments of subjective POV camerawork, Galloway notes that this direct use of subjective camera eye "is marginalised and used primarily to affect a sense of alienation, detachment, fear, or violence" [5] (p. 40). Within these moments of subjective POV camerawork, the viewer is invited into an uncanny space that seemingly puts them in direct contact with the medium.

Christian Metz's [9] book Impersonal Enunciation, Or the Place of Film discusses the problems of this aesthetic, a major one being the absence of a primary character. As Metz notes, without seeing a character onscreen but rather through them via POV, the spectator has a difficult task of trying to understand what the character's reaction is to what the character/spectators is/are seeing. As Metz [9] (p. 90) asserts, "to slip into the gaze ("subjectively"), one must know the person ("objectively").

David Sorfa's [10] more recent article, "Seeing Oneself Speak: Speech and Thought in First-Person Cinema", continues to pick up on the uncomfortableness of the subjective aesthetic. Sorfa claims that the problem is primarily one tied up with narration and turns to the early writing of Julio L. Moreno to unpack this.

Narrative demands a split between the narrator and the narrative, between the person telling the story and the story itself, and that film generally keeps a clear distinction between the facts of the narrative and the way in which these facts are presented to us. First-person cinema confuses this distinction and so first-person cinema struggles to work well because it collapses the narrator into the narrative. In first-person cinema, it is unclear whether what we are seeing belongs to the subjective or objective world and this unintended ambiguity acts against the film [10] (p. 107).

Sorfa [10] (p. 110) goes on to explain that the problem with the subjective shot in film's like Lady in the Lake is that it does not reflect the world but rather "magnifies the gap that exists at the centre of our experience of the world". He goes onto state that this explicit reminder of such non-presence is what makes watching POV films "a profoundly unsettling and [ ... ] unpleasurable experience" [10].

As this essay will argue, the concept of uncomfortableness through a phenomenological POV is something that can be valuable for fiction films through the term that I have coined as hap-tech narration. Hap-tech narration utilises Don Ihde's framework of postphenomenology as a way to understand some of the main technological apparatuses of the cinema-primarily the camera and the screen. The uncomfortable space of POV, understood through a hap-tech reading, affords a new layer of reception towards the film's fiction. After the following understanding of hap-tech narration (set out below), this essay will analyse a range of hap-tech films that consider the POV shot from the perspective of a killer gaze and a victim gaze, and which utilise this "unpleasurable" experience within the film's story.

\section{An Understanding of Hap-Tech Narration}

Hap-tech narration encourages an embodied, multisensory and multitemporal relationship with a viewer by focusing exclusively on subjective camerawork. Fundamentally, the term considers the uncomfortableness of the POV aesthetic and considers how this shot can be strategically used and analysed to consider the awkwardness and uncomfortableness of a specific character's gaze, which as I argue, is generally reserved for killers, victims or socially inept personas in fiction film. 
Hap-tech narration is underpinned and, yet, in direct contrast to Laura Marks' concept of haptic cinema, discussed in her work The Skin of the Film. Within this book, Marks explores the haptic image as a sensuous experience of beauty. Marks employs Vivian Sobchack's work [3] (p. 149), which recognises that cinema is not illusionary "but an extension of the viewer's embodied existence".

Sobchack described this embodied existence through her writings on the cinesthetic subject, a term she coined to describe how viewers experience cinema through their entire body and not just the distant senses of sight and sound. Sobchack employs Maurice Merleau-Ponty to argue that the cinesthetic subject is a hybridised term that describes cinema as an experience involving both "synaesthesia and coenaesthesia" [11] (p. 67). The former indicates an amalgamation of the senses, whereby one will cue a perception in another, such as the loudness of bright colours. Merleau-Ponty's [12] Phenomenology of Perception illustrates synaesthesia through the claims that "[o]ne sees the hardness and brittleness of glass [ ... ] the springiness of steel, the ductility of red-hot steel, the hardness of a plane blade, the softness of shavings" [12] (pp. 266-267).

Coenaesthesia, in contrast, is a term that refers to the holistic potential and perception of one's sensorial being as a whole. Sobchack [11] (p. 68) combines these two meanings to form the cinesthetic subject, stimulating all five bodily senses under the umbrella senses of sight and sound, which triggers affect in the spectator, enabling her to articulate why the viewer feels a range of bodily experientiality when viewing something onscreen. This concept of synaesthesia also provides the foundation for Marks to construct her concept of haptic cinema. This, as she defines, is something that appears to the viewer as an object of interaction, rather than illusion, "which calls upon [a] sort of embodied and mimetic intelligence" [3] (p. 190).

As Marks highlights in the quote above, the relationship between film and viewer, or technology and body, is fundamentally mimetic, enabling screen and viewer to sensuously enfold into what she calls a haptic visuality, which composes a positive sense of feeling and meaning. Haptic visuality permits a viewer to experience a sense of touch with their eyes, usually through the cinematic channel of the close-up. Marks identifies the haptic image as something unsuitable for narrative cinema, arguing that the haptic image, which evokes a tactile sense, "forces the viewer to contemplate the image itself, instead of being pulled into narrative" [3] (p. 163). Marks's work also argues the case that the haptic image frequently elicits a sense of positivity through sensual pleasures.

In contrast, hap-tech narration calls to attention narrativity, specifically through embodiment and the role of the cinematic camera apparatus. Furthermore, sensual pleasure is replaced with the uncomfortableness of subjective camerawork through the negative body surrogates of killers, victims or socially inept character personas. This is what differentiates hap-tech narration from Marks' haptic cinema. Hap-tech narration is also distinguishable through the incorporation of a postphenomenological framework developed by Ihde which utilises his understanding of human-technology relationships.

\section{Postphenomenology}

Adapted from Merleau-Ponty's concept of phenomenology, which explores the structure of human experience between the world and a sensing body, Ihde's postphenomenology considers relationships between bodies and technologies, and how technologies change human experiences. As Ihde explains, "[p]ostphenomenology is a modified, hybrid phenomenology" [13] (p. 23). The "post" within his term accounts for development in the analysis of phenomenological studies, which in his work, uses a philosophy of technology "to probe and analyze the role of technologies in social, personal and cultural life [ ... ]" [13]. Put differently, if phenomenology is an experience of the world, then postphenomenology is an experience of the world through a specific technology.

As Ihde observes, both tools and bodies are everywhere, pervasive across our lifeworld. In particular, Ihde considers how different technologies change, adapt, correct, limit and extend (in a McLuhanesque way) the functionality and ontology of human experience. From eyeglasses that correct and extend human vision to bicycles and automobiles that change our bodily sense of 
speed through transportation, Ihde deliberates upon how a technological apparatus restructures the corporeality and subjectivity of a human user in a postphenomenological way.

Ihde's postphenomenology is inspired by the phenomenological philosophy of Merleau-Ponty and Heidegger's philosophy of technology. Inde has argued throughout his work that all technologies (from hand tools to digital software and hardware) has the ability to modify experience. Ihde argues that technologies can often extend and limit the corporeal body of the user regardless of technological sophistication. Take Merleau-Ponty's [12] well-known example of the blind man's cane for example. In this instance, the cane becomes an extension of touch, which provides "a parallel to sight" [12] (p. 165).

Here, Ihde [14] asserts that such an extension is always balanced by a synchronous reduction. As he explains, the cane user can feel the textured hardness of the pavement through the cane technology but cannot experience its greyness of colour. Furthermore, the user cannot feel the sensation of the pavement's warmth or coldness through the cane [14] (p. 7). The cane tool, therefore, filters certain phenomenological sensations while enhancing others. To put this differently the mode of experiencing something (in this instance, the cane) has a direct bearing on that which is being experienced (the pavement). Here, Ihde is incorporating Edmund Husserl's [15] phenomenological use of noesis which means the mode of experiencing and noema, meaning that which is experienced.

To illustrate this, Ihde [16] describes Husserl's terminology through a blackboard and a piece of chalk. In this instance, the noesis is the chalk (the mode of experiencing) and the blackboard the noema (that which is experienced). Ihde describes how this experience of noema is changed when the noesis of the chalk is substituted for a different tool, such as a dental probe. This instrument, consisting of a fine pick, when traced over the board, affords a different type of experience from that of the chalk. The experience of the board's hardness is still apparent, but the pick also reveals, with distinct clarity, data about the board that the chalk cannot, such as pockmarks or cracks upon the board's surface [16] (p. 9). Thus, the noema of the board is different in accordance with the alternative mode of noesis.

Ihde's concept of postphenomenology hinges on the way that different types of technologies construct alternative modes of experiencing. Within his work, he [17] (pp. 72-108) identifies four different types of human-technology relationships which he describes under the following headings: embodiment, hermeneutic, alterity and background relations, the first two of which are relevant to hap-tech narration. An embodiment-relation for Ihde, is a perception or experience through a technology as a tool synthesises with a body in a particular way. Merleau-Ponty's cane, for example, is an instance of an embodiment relation which (through use) ceases to be an external object and becomes an extension of the blind man's sight, withdrawing into his grip and repertoire of movements. Ihde bases his use of embodiment relations upon Heidegger's [18] concept of ready-to-hand, a term famously coined in Being and Time to describe how a technology withdraws (through the act of use) into its user.

According to Ihde's interpretation of Heidegger, ready-to-hand affords the user praxis or a "practical behaviour" rather than a theoretical one. Praxis binds a human user and technology in a process of withdrawal. In the act of handwriting for example, the pen withdraws into the grip and actions of its user. The pen temporarily fuses with its user, tracing their corporeality whilst, at the same time, changing their experience, which has now become accessible to the lettered technology of the alphabet. Through Ihde's reading of Heidegger, the ready-to-hand relationship posits that when a user is engaged in a task while using a tactile tool, such as a pen to write, a hammer to hit nails or a spade to dig the earth, a process of withdrawal takes place between body and tool, at which point they are synthesised together in the act of writing, hammering or digging. During this process, the user encounters an intuition, competence and inclination through their tool in order to accomplish the task at hand. As Ihde [19] asserts, tools change experiences, which he sets out in the following way.

In phenomenology, the human can be thought of as an experiencer, and the world, an environment that is experienced:

\section{Human}

\section{World}


The arrow stands for the direction of focus or intentionality directed toward the world of something. As Ihde [19] (p. 53) explains, directed actional involvement with a world is not only one-directional, it is also reflexive or interactive. Phenomenology interprets intentionality as not only a distance from and involvement with world, but as reflexive with respect to world. In other words, the world reflects experience or knowledge back onto the human. A second arrow denotes this accordingly:

\section{Human}

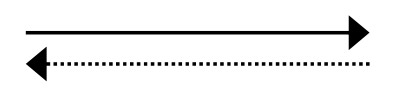

\section{World}

Once we begin to consider the role that technologies play in mediating between humans and world, the relationship changes once more:

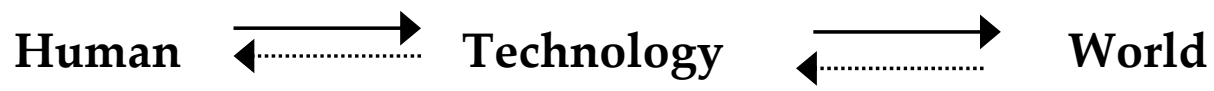

According to Ihde [19] (pp. 53-55), building upon Heidegger's philosophy of technology, when the world of something is mediated through a technological means, the medium alters that which is experienced both outwardly of world and reflexively of self. Through this methodology, we can consider the world of the film through the technology of the camera, and how the viewer of the subjective POV shot seemingly embodies this technological device in order to feel as if they are present within the diegetic world of the film space. Here, they encounter a hollow type of presence within the film's narrative via the direct address of other characters. However, a lack of agency to affect any change upon the screen content is of course in place, leaving the viewer to undergo the second of Ihde's [17] human-technology relationships, which he calls a hermeneutic relation.

A hermeneutical relationship, in contrast to the embodiment relationship of seeing or acting through a technology, is an experience of a technology. Hermeneutic, therefore, pertains to a technology that we read, such as screens, clocks, thermometers, maps, books, or any other tool that marks a separation between a body and a technology. This is in direct contrast to the temporal fusing between body and technology that occurs in embodiment relationships in which the user experiences through the technology. Although the subjective POV camera movement temporally suggests that the viewer is experiencing through the technology (as we would find in an embodiment relationship), the frame of the cinema screen reminds the viewer of the separation between them and the film world, and that the cinema is something that we read as well as feel. As a result, the POV cinema spectator fluctuates between embodiment and hermeneutic states, experiencing a sense of uncomfortableness as they bounce back and forth between these two relationships.

In The Address of the Eye, Sobchack [1] uses Ihde's embodiment relationship to consider the first-person camera movement of Lady in the Lake. She argues that Montgomery's film is fundamentally flawed for failing to translate natural fluent movement. However, what she does not do (and what this essay contributes) is show how such failure to produce natural movement can play a significant part in experiencing the narrative of the film from a postphenomenological vantage. For some filmmakers, POV is embraced. James Cameron, for example, has frequently deployed subjectivity throughout his films, particularly through the robotic sight of the cyborg in The Terminator (1984) [20] (Figure 1).

As Cameron [21] (p. 17) states, "any way in which you can make a film more of a subjective experience for the audience member, the more impact it's going to have". Cameron qualifies this idea through the use of subjective shots in Kathryn Bigelow's Strange Days (1995) [22], which he co-produced, asserting that these moments within the film correctly convey a "sensorially complete reality" [21] (p. 103). Within this film in particular, disorientation through subjective camerawork plays to the strength of the story. The film portrays a number of characters using fictitious VR headsets called SQUIDs (Superconducting Quantum Interference Device). Within the diegesis, this is a technology designed to capture and record subjective experiences, right down to the physiological and olfactory sensations as well as the visual and audible perceptions. The SQUID takes the form of a metallic skullcap that responds directly to its wearer's cerebral cortex. During immersed states, the characters 
and viewers experience a subjective POV that portrays the VR immersion. The unnatural movement of the camerawork signposts the artificiality of the VR device, causing an uncomfortableness on the part of the viewer. Discussing this film, Shaviro [23] has described these moments in the following way.

Events unfold in real time, in a single take, from a single point of view. These sequences are tactile, or haptic, more than they are visual. The subjective camera doesn't just look at a scene. It moves actively through space. It gets jostled, it stops and starts, it pans and tilts, it lurches forward and back. It follows the rhythms of the whole body, not just that of the eyes. This is a presubjective, affective and not cognitive, regime of vision. [23] (p. 62)

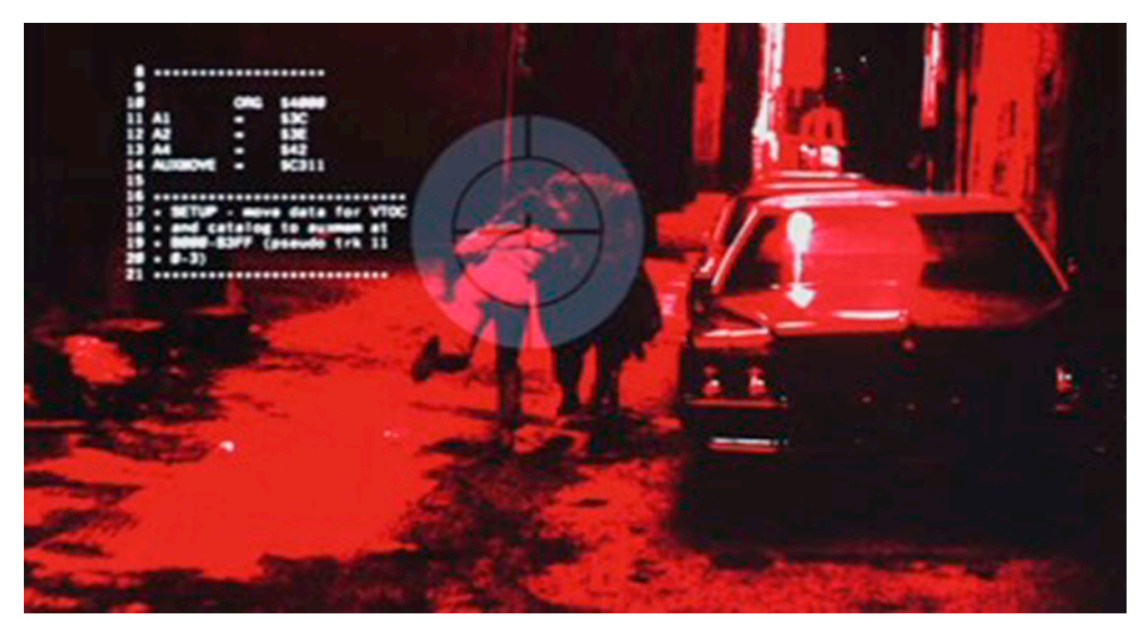

Figure 1. Image from The Terminator (1984) [20].

Shaviro's description is reminiscent of the conflation between an embodiment and a hermeneutic relationship when he highlights the movement of the camera as it follows rhythms of the whole body rather than just the eyes. This uncomfortable use of POV in Strange Days works to translate the anxious or morally corrupt surrogate characters within the diegesis of the film. In accordance with hap-tech narration, the POV aesthetics are reserved for moments of uncomfortableness through the perspective of the killer, victim or socially damaged characters. This comes to fruition during one particular moment of first-person camerawork where physical and moral deficiency are interlocked with one another to present a harrowing attack on a character. This is a moment in which a woman who is being raped is forced to witness her own attack through the eyes of her attacker. She is made to wear a SQUID headset as the rapist remotely connects to her device to make the woman see and feel the experience from his perspective. Victim and killer gaze are thus melded into one.

To summaries Ihde's framework, the movie camera can be considered a specific form of noesis (an experiencing tool) that extends the viewer into the film (an embodiment relation). Full transparency is, of course, impossible, which results in a disorientating experience for the viewer, exacerbated by the edge of the cinematic screen (a hermeneutic relation), which restricts the viewer from achieving full transparency. Consequentially, the POV shot becomes an uncomfortable and awkward viewing experience as external characters directly address viewers who are positioned in the gaze of an invisible protagonist. The viewer of course possesses no agency and can do nothing but observe from their surrogate prison. A notion reminiscent of the closing moments of Spike Jonze's Being John Malkovich (1999) [24], where a puppeteer protagonist loses his supernatural power to control other people and is forced to spend the rest of his existence as an observer from the perspective of a young child's gaze. Arguably, this protagonist, Craig Schwartz (John Cusack), is an awkward character who fits the criteria of hap-tech narration, but, for now, I consider this term and the POV shot in a much earlier film as I turn to the opening of Michael Powell's Peeping Tom (1960) [25]. 


\section{The Camera Eye}

"All this filming is unhealthy." These are the words that are uttered to Mark Lewis (Karlheinz Böhm), the protagonist of Michael Powell's Peeping Tom, which tells the story of a cinematic focus puller by day and voyeuristic serial killer by night. His murderous methodology takes place through the technology of a movie camera that is affixed to a tripod containing a concealed lethal spike. Filming his subjects, Lewis uses the spike to pierce each victim's throat whilst capturing their terror on camera. At a later point, he is shown watching the footage back, reliving the moment while reaching orgasmic gratification through the recorded event.

The film begins with Lewis approaching a female sex worker (Brenda Bruce) with the hidden camera buried within his duffle coat. As Lewis nears the woman, the mise-en-scène jumps into the technological gaze of the subjective camera's eye. From here, the camera eye becomes the dominant vision as we (the viewer) follow the woman to her home and up the stairs to her bedroom where she proceeds to undress (Figures 2-4).

As she unzips her skirt, the camera looks away, revealing the silhouetted hand of Lewis across the lens as he releases the spike. The focus swivels back onto the woman whose mood quickly changes to unbridled fear as she recoils from the approaching camera, screaming directly into its crosshair lens.

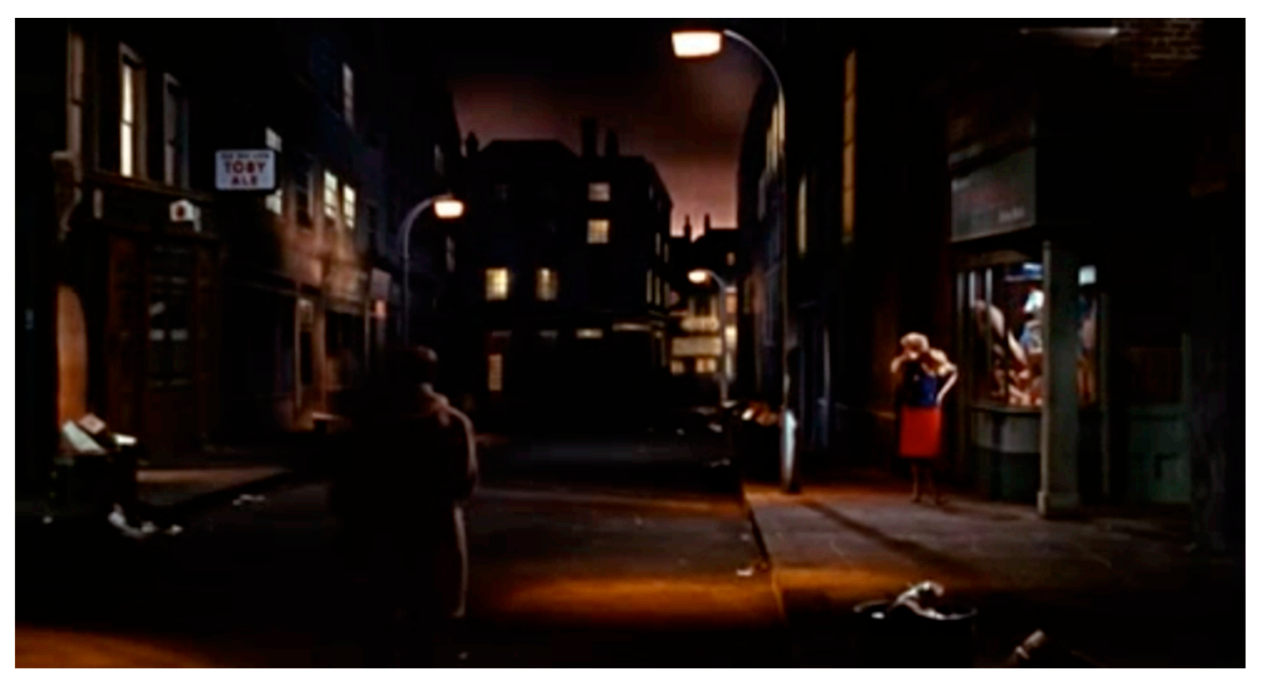

Figure 2. Image from Peeping Tom (1960) [25].

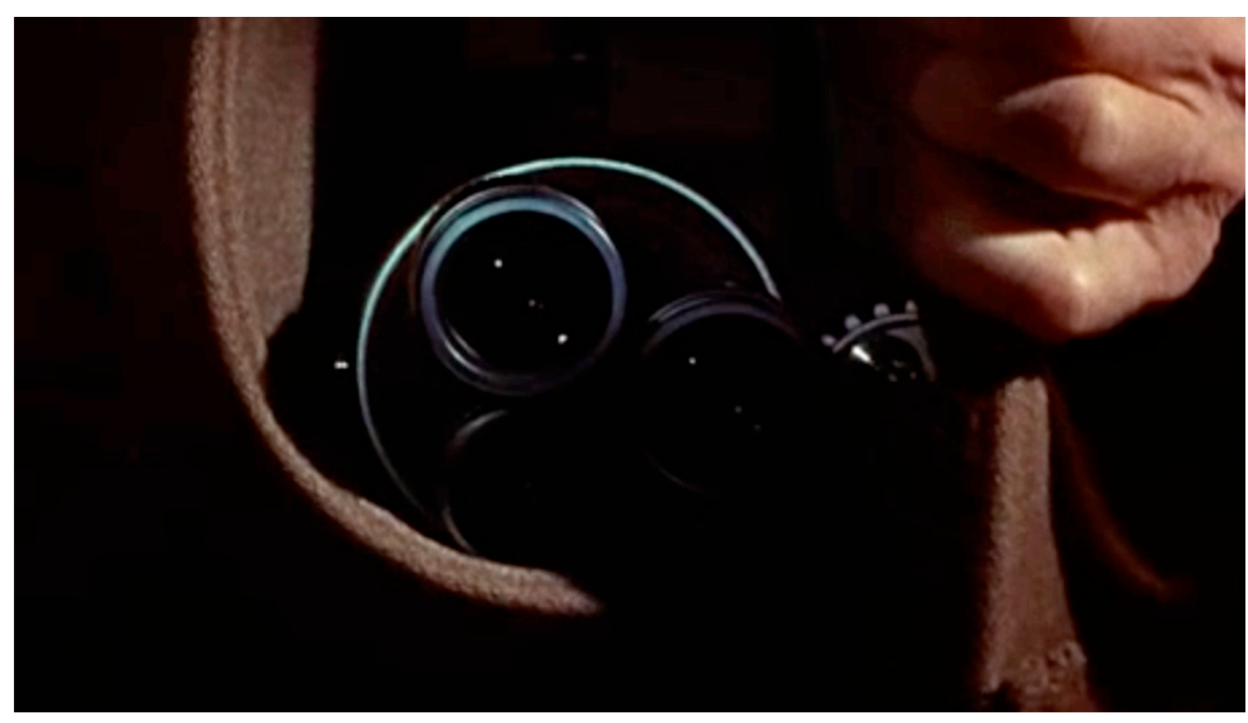

Figure 3. Image from Peeping Tom (1960) [25]. 


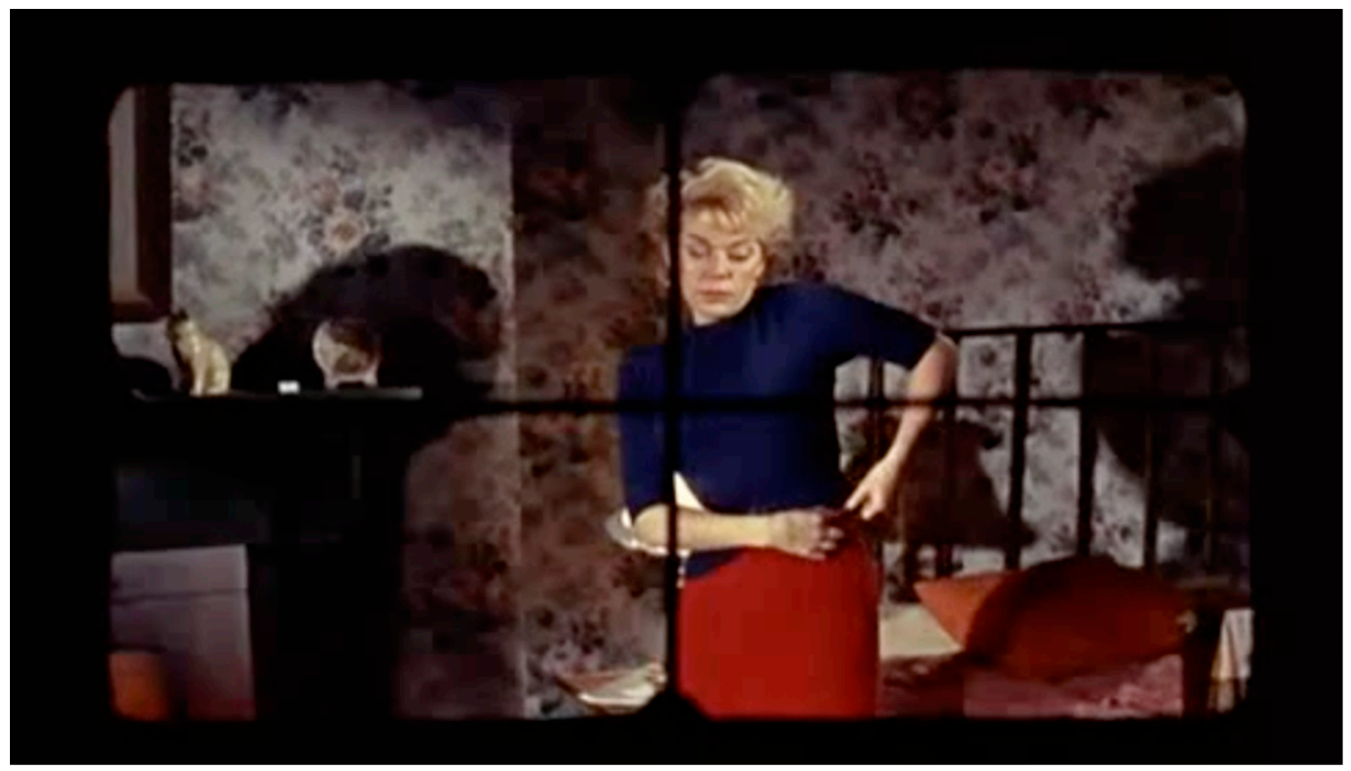

Figure 4. Image from Peeping Tom (1960) [25].

Within this sequence, the view from the camera becomes a surrogate body for the spectator. I adopt the term "surrogate" from David Bordwell's [26] paper, "Camera Movement and Cinematic Space", which considers camera movement as "a persuasive surrogate for our subjective movement through an objective space" [26] (p. 23). A surrogate, as Bordwell [26] states, is "a basis for the orthodox comparison between the camera and the human body". In this instance, the surrogate film body is an unseen vessel that simultaneously extends and limits the corporeal sensations of the viewer, which, as Ihde [26] (p. 20) identifies, is a key concept of the embodiment relation. The subjective viewer is simultaneously extended into and cordoned off from the diegetic world of the film (the noema) through the noesis of the camera technology, which contributes to a perception of unease. As mentioned above, I have come to notice that the POV aesthetic is used primarily in narrative cinema to represent three specific types of surrogate body which consists of the killer, the victim or the socially awkward character, to which Lewis from Peeping Tom is a case in point.

As noted, Lewis' concealed camera is shown hidden within his duffel coat at waist level, yet when we adopt the proceeding camera gaze upon the prostitute (signified by the crosshair), she stares straight into the camera lens at eye level. If the arrangement of this shot is for the viewer to adopt the gaze of the camera exclusively, rather than the cameraman, then the mise-en-scène should be at an upward 45-degree angle from Lewis' waist. Instead, the camera eye (confirmed by the crosshair) is in line with the woman's corresponding eye (Figure 5), yet she does not acknowledge the camera, which, as far as the spectator is concerned, remains hidden within the coat. As Edward Branigan [27] (p. 157) notes, "in a POV shot the specific angle of view is importantly tied to the attention and awareness of a specific character and thus the angle must be captured and held in working memory by the spectator". Therefore, the question is raised as to whose perspective the viewer is adopting-camera or Lewis?

The discordance among these two perspectives seems too obvious to be a continuity error, so instead can be considered a deliberate nuance that emphasises the narrative aspects of the film through the postphenomenology of the camera technology. The character of Lewis and the first-person camerawork that mediates this opening sequence are both awkward and uncomfortable. The camerawork simultaneously extends and limits the viewer into this troubled surrogate vessel that clashes somewhere between human body and technological artifice. This friction serves as a way to consider the character of Lewis, the uneasy protagonist that the viewer is tethered to.

For Lewis, the deaths of his victims become a necessary means in order to harvest the emotion of fear, which he then preserves on camera to watch at a later point in time. In the diegesis of the film, we learn that the external fear of others is what motivates Lewis to commit his crimes. During 
an intimate scene between Lewis and Helen Stephens (Anna Massey), a neighbour he becomes close to, he explains how his father was a biologist and author on the subject of fear and the nervous system and used his son as a guinea pig for his research. Consequentially, Lewis grew up being subjected to both fear and the camera in a mitigated version to what Lewis now inflicts upon his victims. We learn how his father would frighten his son, documenting the results on camera. We see, as Helen does, home movies of a crying child, woken in the night by the biologist, terrifying his son while recording his response. We are invited to sympathise with Lewis in the knowledge that he never appreciated a moment's privacy whilst growing up. His corrupted killer appetite from behind the lens, thus, stems from childhood victimisation in front of it.

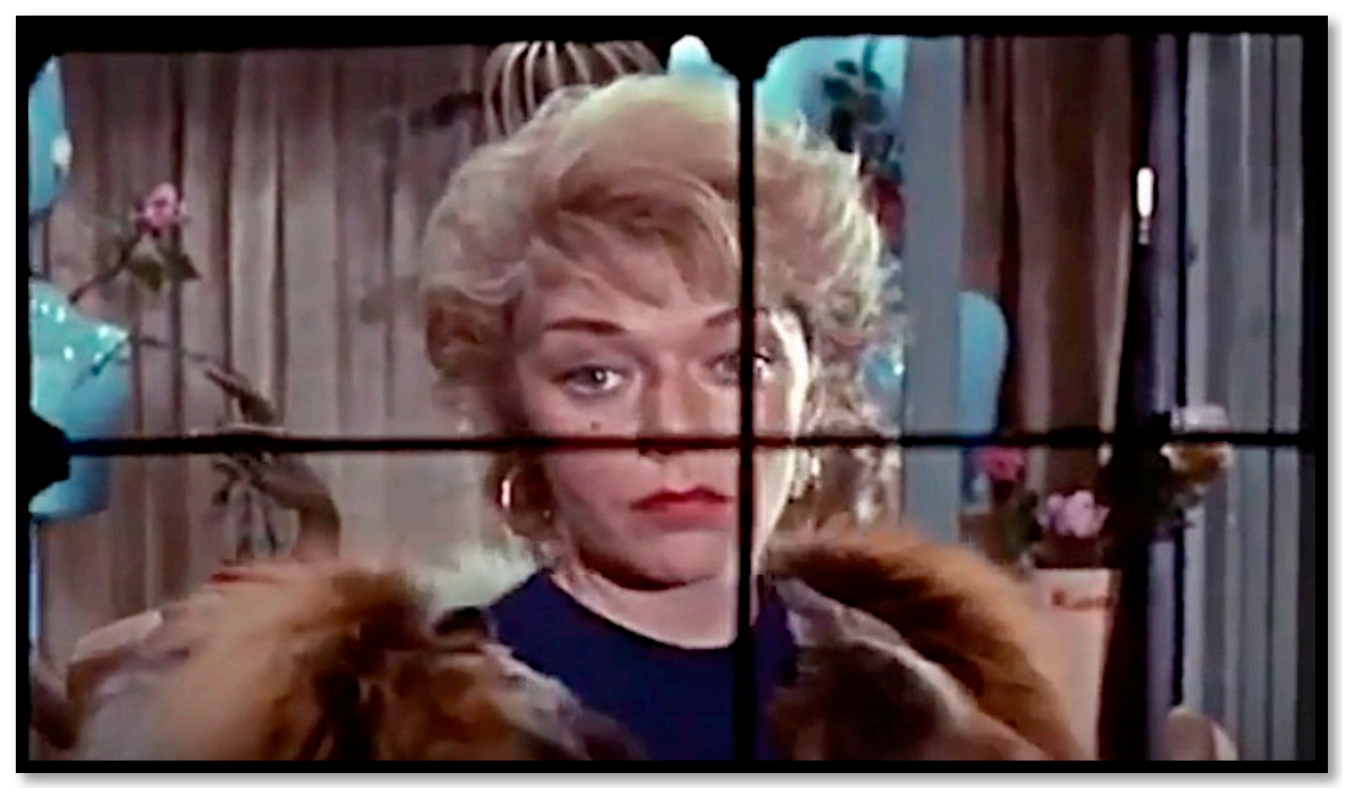

Figure 5. Image from Peeping Tom (1960) [25].

As the hidden camera's view from beneath the duffel coat is at the wrong angle, combined with the prostitute's initial unperturbed expression as she gazes straight back into the lens, I propose that the viewer at this moment is not looking through the actual camera that Lewis is carrying but, instead, is rather looking through the eyes of Lewis; a victimised/killer protagonist who over time has become distorted with technological vision. The invasion of the camera into Lewis's childhood takes its toll upon the adult Lewis, represented through this POV moment of hap-tech narration. The subjective shot, thus, portrays an ebbing away of organic selfhood, to leave an emotionally fragmented and cyborg-like surrogate, denoted through a reliance on the camera crutch to feel alive. Lewis' warped technological sight is what drives the film's story. The viewers engage in these events from the perspective of the warped protagonist, which is emphasised in these explicit subjective moments.

Lewis' discomfort and social awkwardness is shared through the subjective camera's restriction of space and demarcating frame, while the crosshair lens denotes his killer instinct as it searches for a target. The viewer, who has no agency, is trapped within this surrogate body; a prison they cannot control but only observe from. The negative sensations of the camerawork reinforce the negative character traits of the surrogate body through the entwinement of moral deficiency, reprehensible killer and vulnerable victim, similar to the POV moment in Strange Days discussed above.

In Shaviro's [23] analysis of the POV aesthetics in Strange Days, he claims that a signature of anonymity prevents him from identifying with the characters, and that the POV gets in the way of the story. But by stepping back from this and seeing how distancing can be used beneficially to portray negative character traits or experiences, subjective camerawork can become replenished with narrative value. The viewer has access to experience the story of the film through the eyes of a corrupted character so that they (the viewer) may, to some extent, see and feel as they do. Accordingly, distancing 
in film need not be an invalid character trait and instead provides viewers with a deficient perspective to embody a corrupt character through hap-tech narration, where form mirrors content.

Subjective camerawork is a sensation that is at both times natural and artificial, human and synthetic, and is congruent with a particular type of dehumanised character within a film's story. This is because the surrogate vessel, the unseen body that the viewer inhabits (presented through subjective camerawork), is a friction between that which is natural (the concept of a corporeal body) clashing with that which is technological (the camera) which makes up the essence of hap-tech narration.

Through this framework of hap-tech narration, a pattern begins to emerge, as most uses of subjective cinema entails some form of distressing or anxious imagery. Galloway [5] (p. 46) highlights that the subjective shot "generally signifies some type of negative vision", but hap-tech narration can be used to rationalise why this is the case. In addition to Ihde's human-technology relationships, and in line with Shaviro's analysis, the subjective POV shot is something of a departure from identification or empathy with characters, as considered in A.W. Eaton's [28] paper "Robust Immoralism". Within Eaton's work, the author considers a formula for what she calls rough heroes, a term that describes morally ambiguous characters (antiheros) who the spectator is simultaneously invited to identify with and be repelled by. The charismatic mafia boss of Tony Soprano (James Gandolfini) from the HBO series The Sopranos [29] is one example amongst many that drives Eaton's work, which she describes in the following way. "Although the rough hero is supposed to be morally hateful, he is also supposed to be a hero; that is, a sympathetic, likeable, and admirable protagonist. Many techniques achieve this effect" [28] (p. 285). In Noël Carroll's [30] paper, "A Response to A. W. Eaton", the author succinctly summarises how these techniques are achieved into four strategies. As Carroll's analysis of Eaton asserts, rough heroes are formed first by, "narrating from the relevant character's point of view to the exclusion of rival viewpoints" [30] (p. 374). Staying with The Sopranos example, this is why the viewer sympathises with Tony rather than his mother "because the authorial slant stays with Tony's perspective" [30]. Thus, identification with Tony "can be achieved easily by just keeping rivals offscreen" [30]. This, however, does not translate to hap-tech narration because the character that the viewer is supposed to be identifying with is also kept off-screen.

In the opening moments of Peeping Tom, Lewis is invisible to the spectator. We do not see him but rather through him as external characters directly address us. As Tom Brown [31] highlights in Breaking the Fourth Wall: Direct Address in Cinema, "generally, direct address will be the province of a single character and that character is often the protagonist or the principle agent of the narrative" [31] (p. 13). In Peeping Tom, this is not the case, as the direct address comes from the prostitute as the protagonist is kept off-screen, making identification with him problematic and uncomfortable even before the heinous crime is committed. This highlights a fundamental difference between the term point-of-view that Eaton uses and the POV shot that hap-tech narration uses, which can be differentiated through Branigan.

In Point of View in the Cinema: A Theory of Narration and Subjectivity in Classical Film, Branigan [32] claims that a POV is an approximation of what a character sees from their vantage within the film's diegesis, while a subjective shot is the precise perception of a character, as if the viewer is anchored inside of them. This is what George M. Wilson [33] (p. 86) calls "directly subjective narration" and what I call the POV shot. Eaton's use of point-of-view, like Branigan's, is one that portrays the character in the mise-en-scène while inviting the viewer to see events from their perspective. Hap-tech narration, however, utilises a POV shot to precisely see what a character sees while keeping them distant from the character, distorting such identification.

Returning to the rough hero, the second strategy is the portrayal of the rough hero's nemeses as being worse than them. Again, this fails to work for hap-tech narration in which the subjective POV is often dominated by a killer's perspective, a socially awkward character or a vulnerable victim gaze. Even in this latter example, as we will see in the Diving Bell and Butterfly (2007) [34], the external characters are presented in a way of ultimately helping the victim or showing concern, leaving hap-tech narration to depart once more from the rough hero. The third strategy of the rough hero pertains to 
a vigilante character seeking justice, often because the normal channels of justice within the diegesis have not worked. To some extent, Paul Verhoeven's Robocop (1987) [35] (which has a number of subjective moments within it) fits here, as it involves a cyborg seeking revenge on those responsible for his death prior to his resurrection as a machine. Martin Scorsese's Taxi Driver (1976) [36], which I will come onto, also utilises a revenge plot and incorporates subjective camerawork to emphasise a warped sense of justice. This strategy of justice, however, ultimately falls apart for the majority of hap-tech narration, which considers the unjustifiable killer gaze just as much as the identifiable victim one.

Finally, the fourth strategy involves the investment of "morally positive traits, such as devotion to family" [30], intelligence, attractiveness and courage. Many of the examples that I consider to be hap-tech narration are seen through the eyes of isolated characters with estranged or deceased families. Attractiveness or courage within hap-tech narration is usually tenuous or exists as character traits once the spectator is removed from the surrogate POV gaze of the character, as we will later see in Dark Passage (1947) [37]. Consequentially, hap-tech narration stands apart from Eaton's concept of the rough hero.

\section{POV and FPS}

Galloway [5] uses the subjective shot as a template for first-person shooter (FPS) games by localising his discussion of the subjective camera to a corpus of weapon wielding aesthetics within narrative cinema. In addition to Peeping Tom, numerous examples of this can be seen in Alfred Hitchcock's Spellbound (1945) [6] (Figure 6), Clint Eastwood's American Sniper (2014) [38] and Ilya Naishuller's Hardcore Henry (2015) (Figure 7) [39] to name just a few. Within the subjective moments of these films, the viewer is temporarily placed into the body of a character or weapon that is intending to kill. Following Galloway's observation, this highlights how the use of subjective camerawork in film usually portrays a hallmark of weaponry.

This is something that Paul Virilio [40] explores in detail in his book War and Cinema: The Logistics of Perception, where he illustrates how the development of cameras took influence from firearms.

In 1874, the Frenchman Jules Janssen took inspiration from the multi-chambered Colt (patented in 1832) to invent an astronomical revolving unit that could take a series of photographs. On the basis of this idea, Étienne-Jules Marey then perfected his chronophotographic rifle, which allowed its user to aim at and photograph an object moving through space [40].

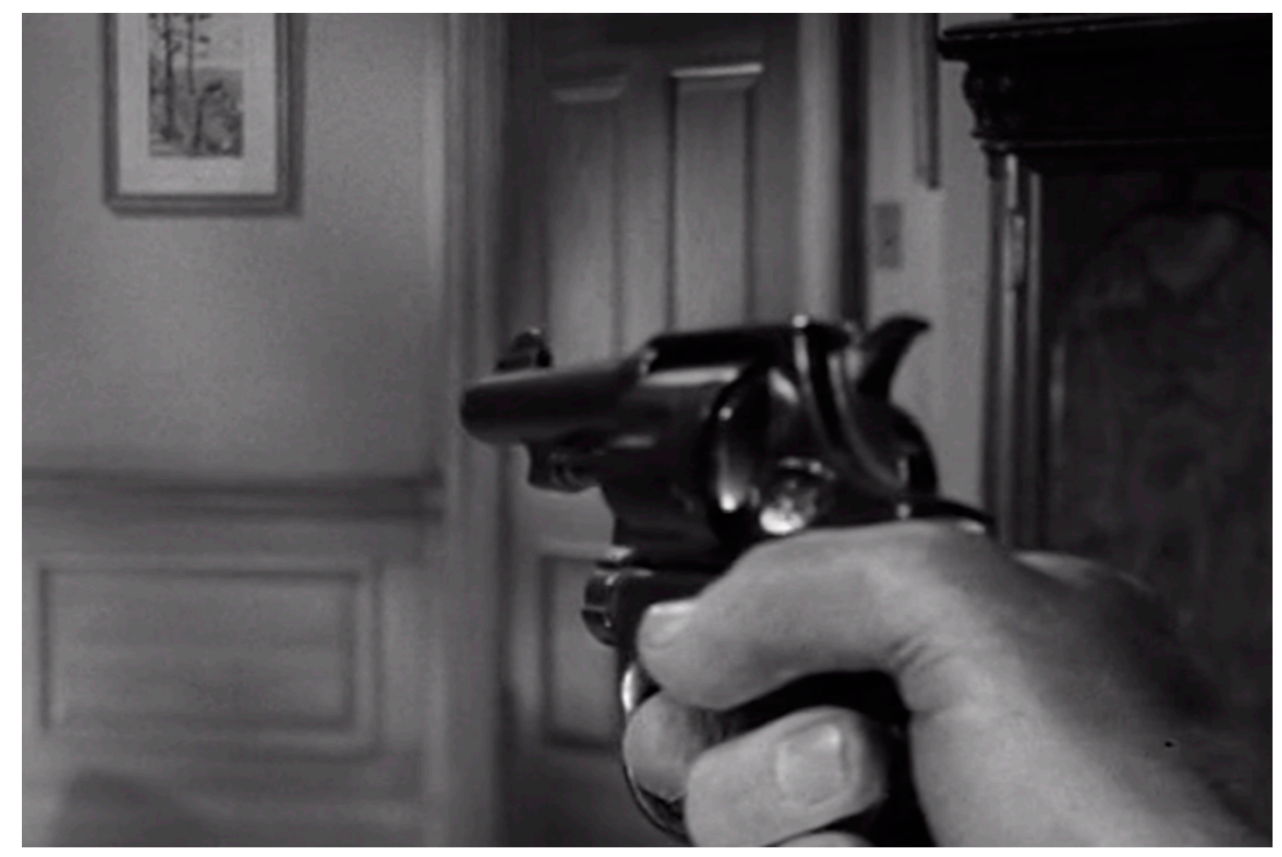

Figure 6. Image from Spellbound (1945) [6]. 


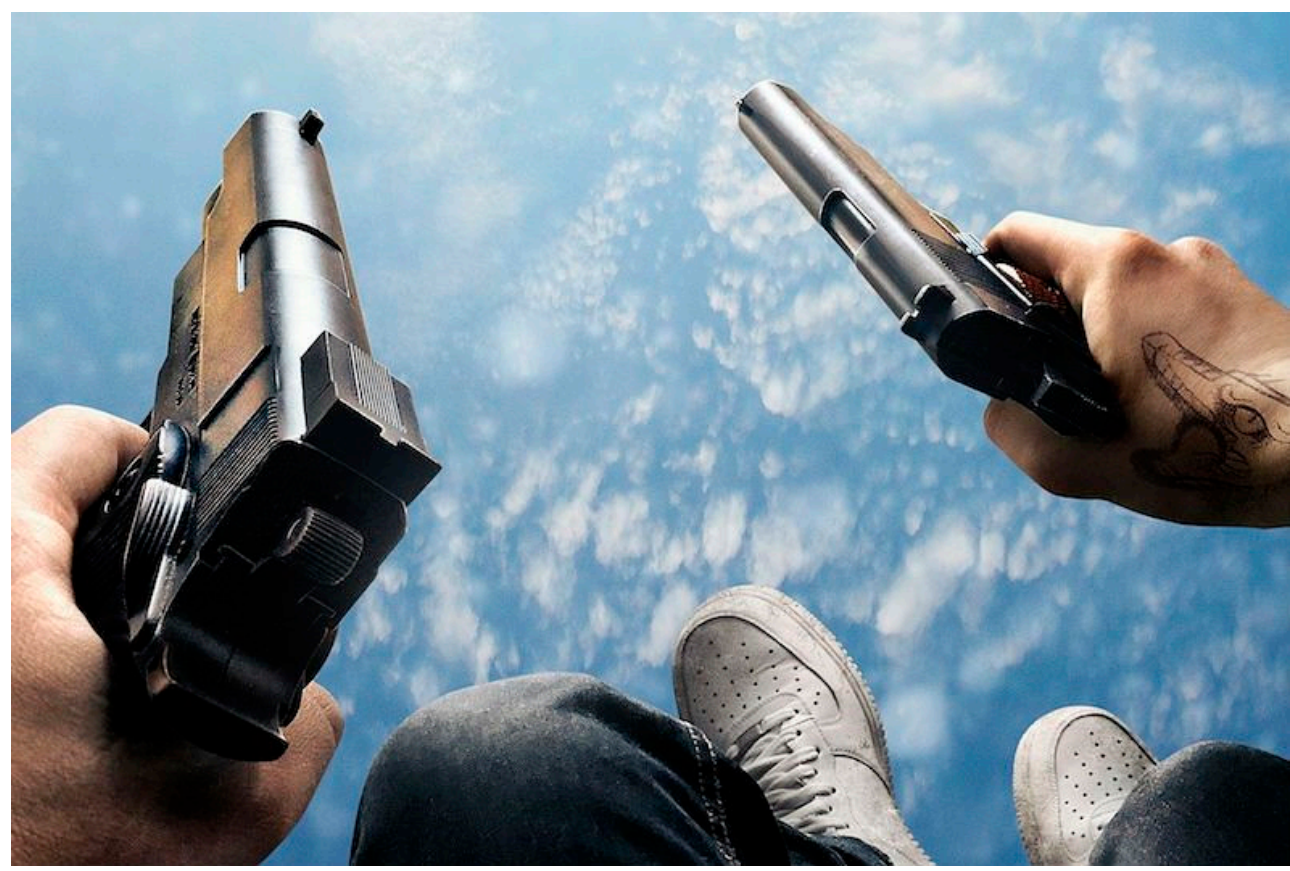

Figure 7. Image from Hardcore Henry (2015) [39].

Consequentially, as Virilio goes onto explain, Marey's chronophotographic rifle became "both precursor of the Lumière brothers' camera and direct descendant of the Colt revolvers and cylindrical guns" [40]. The movie camera is, thus, a by-product of the gun, a notion that is affirmed by Friedrich Kittler [41], who proclaims in Gramophone, Film, Typewriter, how "the history of the movie camera [ ... ] coincides with the history of automatic weapons [where] the transport of pictures only repeats the transport of bullets" [41] (p. 124). Subjective moments in films such as The Terminator, Robocop and Hardcore Henry reinforce this idea. The latter in particular, which is subjective from start to finish, consists mainly of the gaze through a cybernetically modified man who is turned into an augmented killing weapon within the film's diegesis.

Hap-tech narration, however, is more than simple identification between subjective camerawork and gun similarity. Instead, it can be considered a tool to analyse how the POV aesthetic folds back into the story, reflecting a particular type of character body vessel that a viewer inhabits. In Scorsese's Taxi Driver, for example, a standout moment of explicit hap-tech narration is reserved for a shot in which Travis Bickle (Robert De Niro) takes up a gun from an arms dealer and aims it out of a window. Although the majority of this film is portrayed from the perspective of Bickle as he adjusts to civilian life after the Vietnam War, it is this explicit moment of gun handling that feels the most distinctive in its subjectivity. As Bickle takes up the weapon and nears the window, the mise-en-scène jumps into the gaze of what feels to be a smaller, lighter camera, perhaps operated by the actor. This lighter camera traces the movement of the outstretched gun, as Bickle's first-person gaze pans the street in a downward trajectory from behind the weapon searching for a target (Figures 8 and 9). This is a crucial moment within the film because it indicates the change in course that the narrative takes, where homicide becomes the only option left for the solipsistic character.

Hap-tech narration, thus, adheres to a method of analysis broached by Ian Garwood's [42] book The Sense of Film Narration in which a film's sensuous attributes bleed into its fictionality. Garwood's book investigates how moments in cinema that accentuate the senses "contribute fundamentally to a film's dramatic rhetoric" [42] (p. 3). 


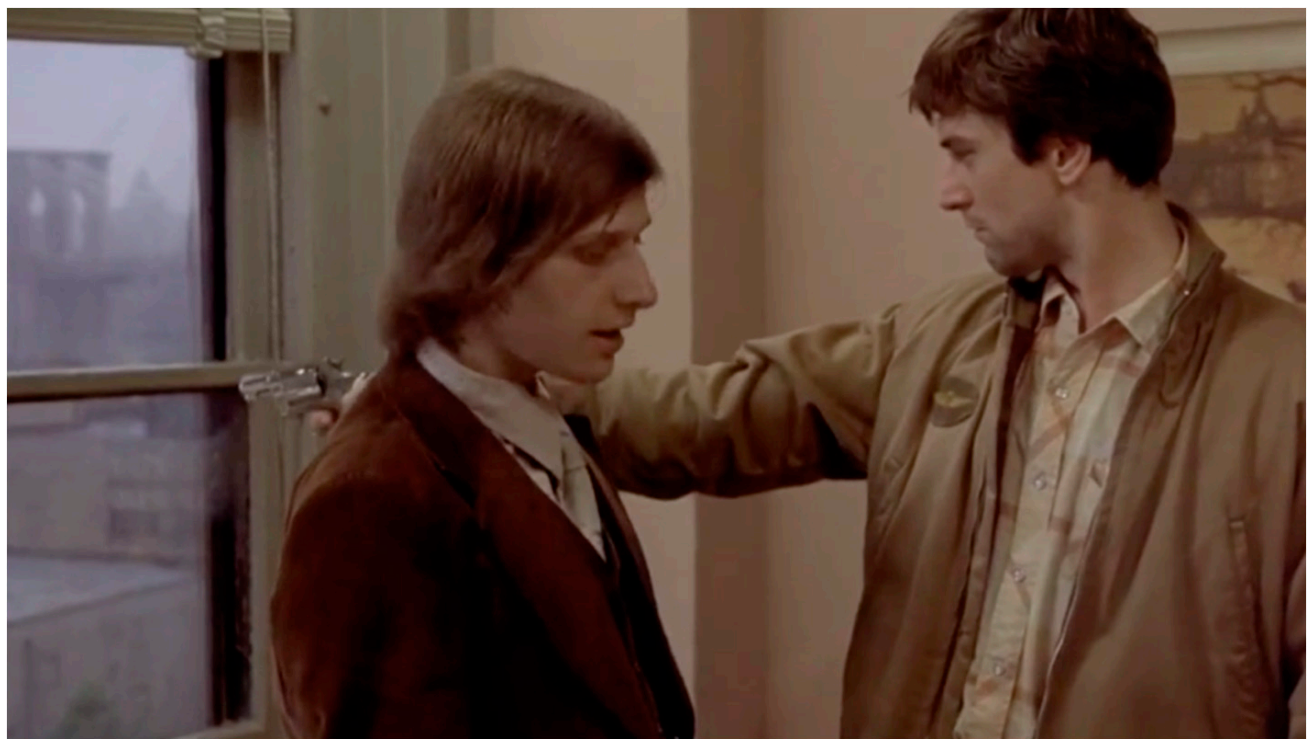

Figure 8. Image from Taxi Driver (1976) [36].

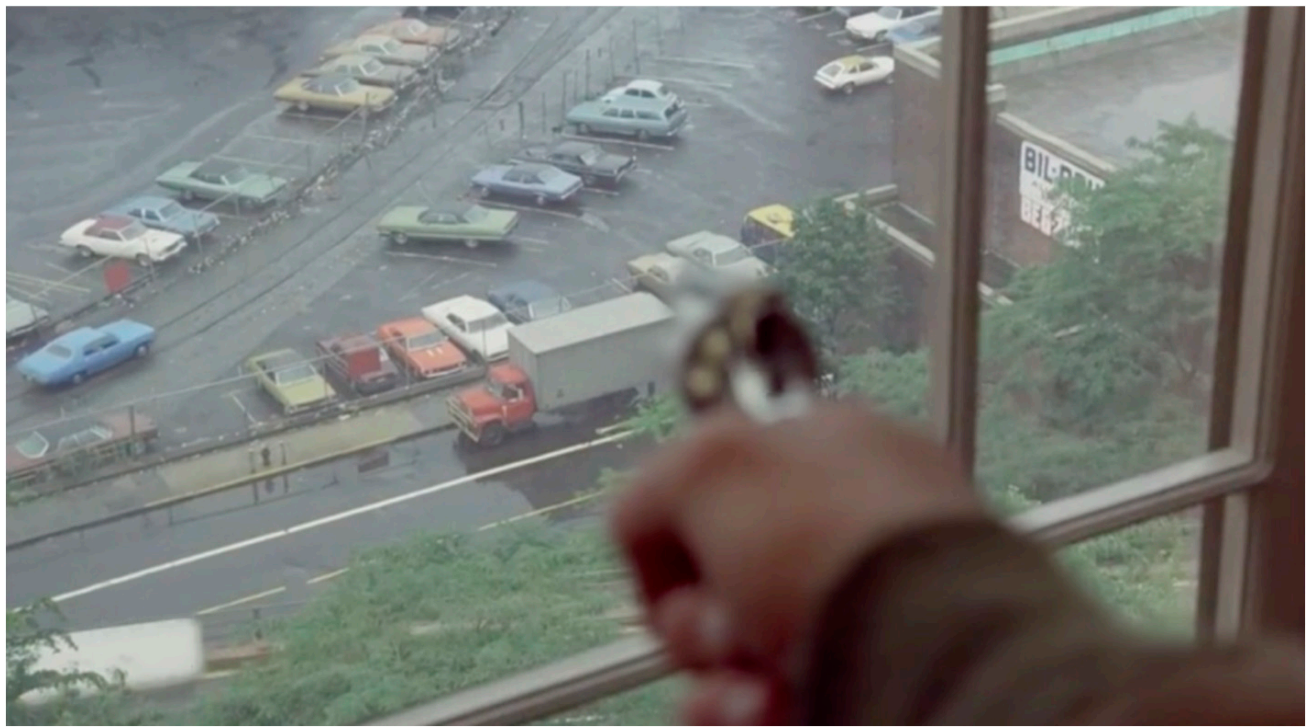

Figure 9. Image from Taxi Driver (1976) [36].

One particular example, perhaps appropriate here for its subjectivity, is his analysis of the character Zurg from Disney's Toy Story 2 (John Lasseter, 1999) [43]. Zurg is a caricatured evil robot who naively believes the conceit that he is an overlord rather than a toy. Unlike the other toys in the film who know what they are, Zurg is not privy to the same information and his lack of insight about who or what he is emerges through subjective POV camerawork. As Garwood notes, Zurg's perspective is illustrated through a distorted and constrained type of vision that looks out of a mask-shaped viewfinder [42] (p. 78) (Figure 10). Zurg's sight is an impoverished red with a crosshair target, reminiscent of the killer-cyborg vision from James Cameron's The Terminator (Figure 1) and stands in contrast to the rest of the film's rich mise-en-scène and camerawork. As Garwood suggests, Zurg's low-quality sight befits his deficient characterisation of a clichéd villain, a killer who tenaciously tries to bring harm to the film's heroes [42]. Zurg's repeated cry, "destroy Buzz Lightyear", shows that he occupies a deficient type of character body, a body illustrated by and suited towards hap-tech narration. 


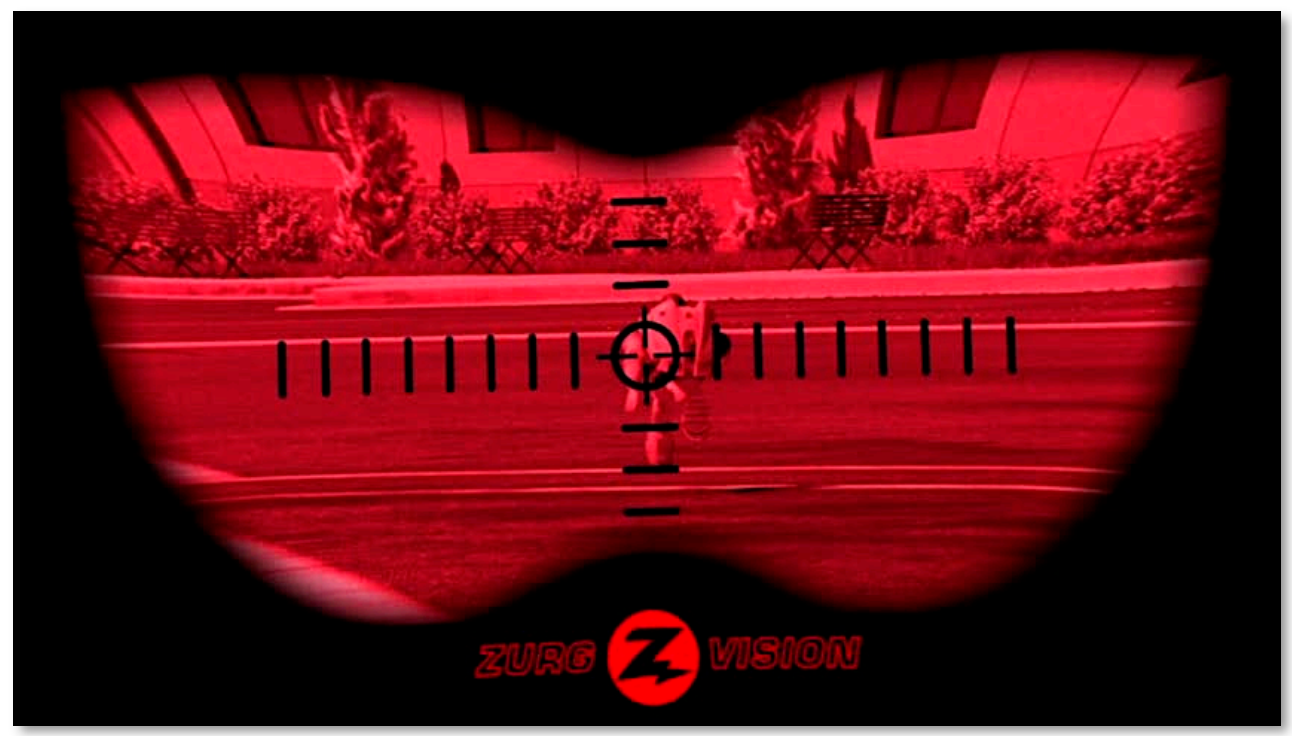

Figure 10. Image from Toy Story 2 (1999) [43].

\section{Hap-Tech Narration in Dark Passage}

As stated, anxiety through the subjective surrogate killer is one part of what hap-tech narration entails. Another relates to a deficient type of body vessel that is portrayed through the notion of a fictional victim. Each of these negative surrogate body vessels fall in line with Maxine Sheets-Johnstone's [44] book, The Primacy of Movement. Within this work, Johnstone explores how a person's movements can define their character. As she argues, humans "intuitively equate aliveness with movement" [44] (p. 117) and do so from birth where we immediately come into the world kicking and screaming. "This primal animateness, this original kinetic spontaneity that infuses our being and defines our aliveness, is our point of departure for living in the world and making sense of it" [44].

Thus, who we are, according to Johnstone, is defined by how we move as we develop a repertoire of "I cans': I can stretch, I can twist, I can reach, I can turn over, and so on" [44]. As she notes, humans kinetically grow into their bodies and discover themselves through such movement. Following Sheets-Johnstone, hap-tech narration involves a surrogate character's movements (represented by the subjective camera), affording the spectator a feeling of "aliveness", and sense of being-in-the-world. Access into the film world through the camera is, thus, balanced by the screen and camera movement, which limits and constrains corporeal freedom. Inevitably, this produces a deviant, corrupt or deficient type of body vessel, which is the essence of hap-tech narration.

An early example of this can be seen in Delmer Dave's film, Dark Passage, which presents a story through the eyes of a corrupted and detrimental body vessel in the form of Vincent Parry (Humphrey Bogart), an escaped convict from San Quentin Prison serving time for the alleged murder of his wife. The film begins with Parry's breakout, portrayed with an establishing shot of a truck leaving the prison before closing in on the image of a metal barrel. Fingers surreptitiously splay out onto the brim of this barrel, denoting the concealment of someone inside (Figure 11). The barrel then begins to shunt back and forth, eventually spilling off the truck and rolling downhill into an adjacent field. As the barrel gyrates, we suddenly adopt a subjective view from inside the tube looking out upon a spinning world. When it finally rests, Parry exits the drum, but the mise-en-scène holds its position for a few seconds from inside the barrel, watching as the convict strips his prison garb.

From here, the viewer jumps into Parry's perspective (Figure 12) as he makes his way through the bucolic foliage, alert with rapid camera movement to the nearing sound of police sirens.

The camera used to produce these subjective sequences within the film was a $35 \mathrm{~mm}$ Arriflex [45] (p. 17), which revolutionised the filmmaking practice in significant ways [45]. This was fundamentally owed to its unique prism reflex viewfinder that enabled the photographer to see exactly what was being 
shot. Film cameras before this had viewfinders either to the side or above the taking lens. As a result, the viewfinder could not produce a perspective exactly the same as the lens. This was what was known as the parallax error, which meant displacement of the apparent position of an object in the optical centre of the viewfinder and that of the taking lens. This was usually overcome, as Leo Enticknap [46] (p. 38) states, by "skewing the angle of the viewfinder lens slightly - in order for the former to give a reasonably accurate view of what the latter will record". However, as he also notes, slight errors could still occur, particularly when filming close subjects, such as hands, which are often included in subjective films. This, in part, contributes to the erroneous look and feel of subjective movement in Lady in the Lake. The Arriflex's reflex viewfinder solved this issue for Dark Passage with a system of mirrors that "eliminated parallax problems, making it the first $35 \mathrm{~mm}$ portable camera to offer a level of functionality like that of a full-scale studio camera" [46].

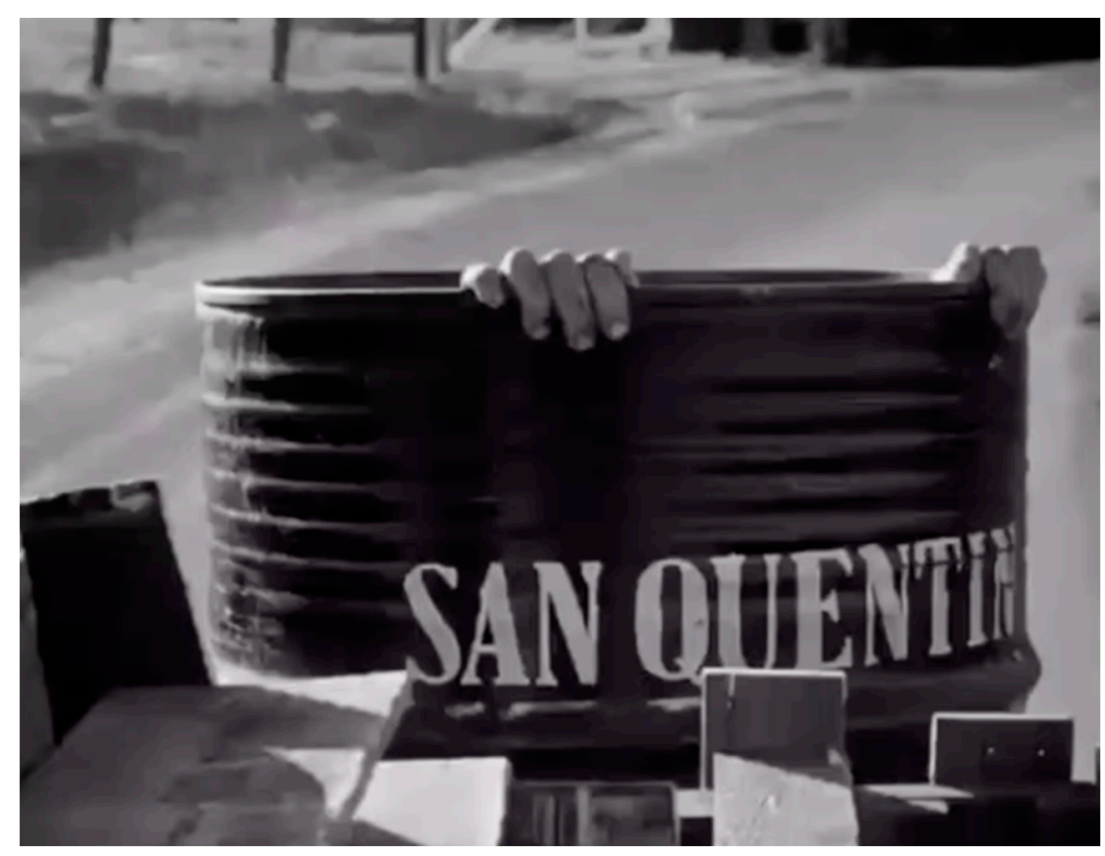

Figure 11. Image from Dark Passage (1947) [37].

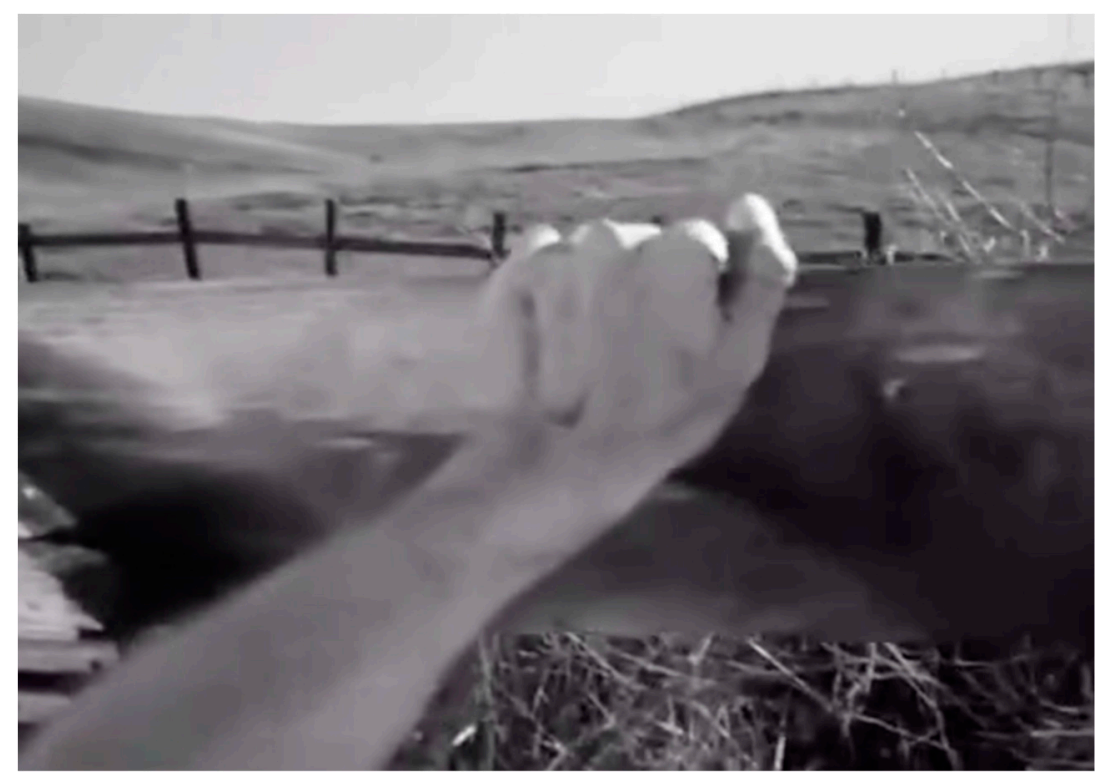

Figure 12. Image from Dark Passage (1947) [37]. 
As a result, movement feels freer and more authentic denoted by the imagery through Parry as he runs, scales a fence, flags down and enters a car in what appears to be, for the most part, one continuous take. The viewer is extended into the film. However, there does remain an awareness and uncomfortableness of the noesis of the camera apparatus, and in keeping with the alternative side of hap-tech narration, the technology does end up limiting corporeality together while extending it. Daves highlights some of the problems the Arriflex had in passing itself off as a real lived-body in a logbook he kept about his film.

Actually, a man walking sways as he steps from one foot to another and, to a certain degree, rises and falls with each step. However, our eyes have a 180-degree angle, whereas the lens angle is restricted. To date, we have used the $35 \mathrm{~mm}$ lens as the nearest to normal eye quality. It is obvious that the more restricted the field, the more noticeable the vibrations will be, so $50 \mathrm{~mm}$ on and up would only serve to increase our handicap on walking shots-conversely, the widest angle lenses that more nearly approximate the width of angles as seen by the eyes suffer from distortional qualities and movement, so that the outer perimeter of the aperture seems to fold in when the camera is in motion. [45] (p. 19)

As Daves illustrates, whichever option he was to choose in presenting natural movement would inevitably be filtered by the intrusion of technological noise. As a result, the viewer experiences an impaired sense of physical identity. But through deployment of hap-tech narration, this can become beneficial to the film's story, particularly as the camera body's impairments become mapped onto an impaired type of character.

In accordance with Sheets-Johnstone's [44] work, which argues how personhood is predicated on movement, we can see how Parry's impaired technological camera/body movement constitutes his impaired fictional character traits. Within the film's diegesis, Parry is a convict, a condemned man on the run, escaping a life sentence following the crime of uxoricide. But he is also additionally revealed as a victim body too. This shift from corruption to victim is disclosed after Parry's escape when he is helped by a woman, Irene Jansen (Lauren Bacall), who divulges to Parry/the viewer how she knows he was framed. With her help and belief in his innocence, Parry is portrayed in a new fictional light as a casualty of justice. This victim body culminates in a later sequence in which Parry undergoes facial reconstructive surgery with black-market practitioner, Dr. Walter Coley (Houseley Stevenson). This sequence is particularly disconcerting and emphasises Parry's new established role as vulnerable victim. As Coley administers us/Parry with an anaesthetic, he begins to callously toy with us about botched facelifts and innuendo as to why he was dismissed from professional practice (Figures 13 and 14).

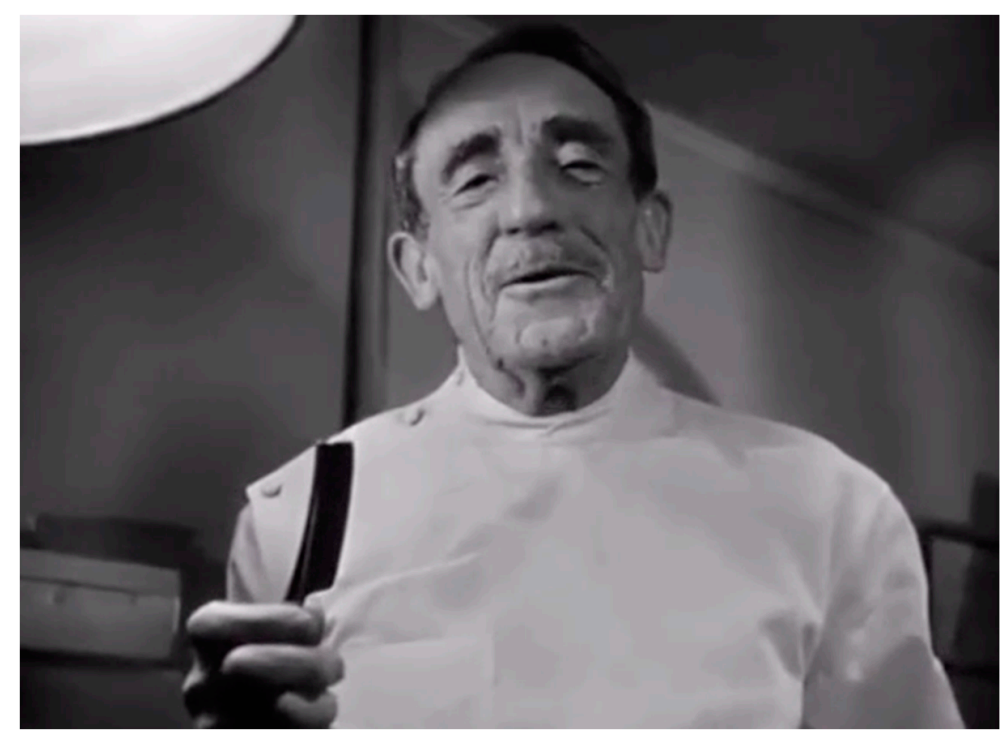

Figure 13. Image from Dark Passage (1947) [37]. 


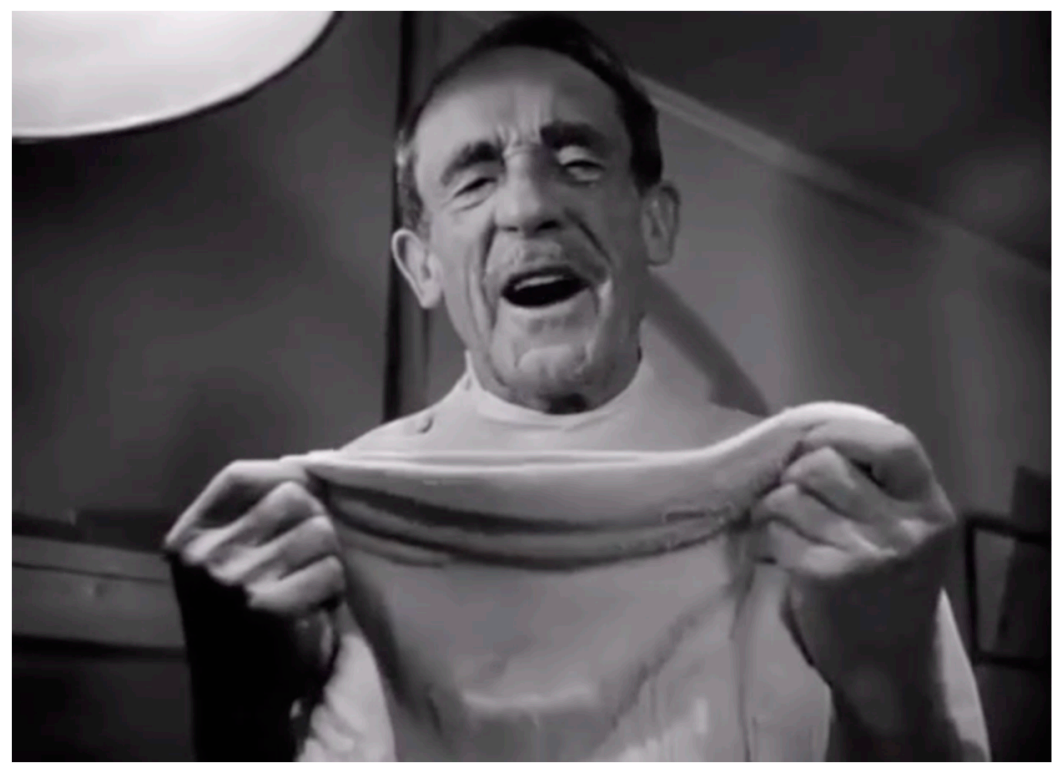

Figure 14. Image from Dark Passage (1947) [37].

The drug in Parry leaves him/the viewer physically weak and in a state of vulnerability, denoted by a blackout as Coley places a flannel over Parry's eyes, blinding the viewer's sight as the doctor readies himself to shave us in preparation for the surgery. This darkness cues a paranoid psychedelic dream from Parry (Figure 15) in which Coley's laughing face repeatedly chants, "ever seen a botched plastic job?"

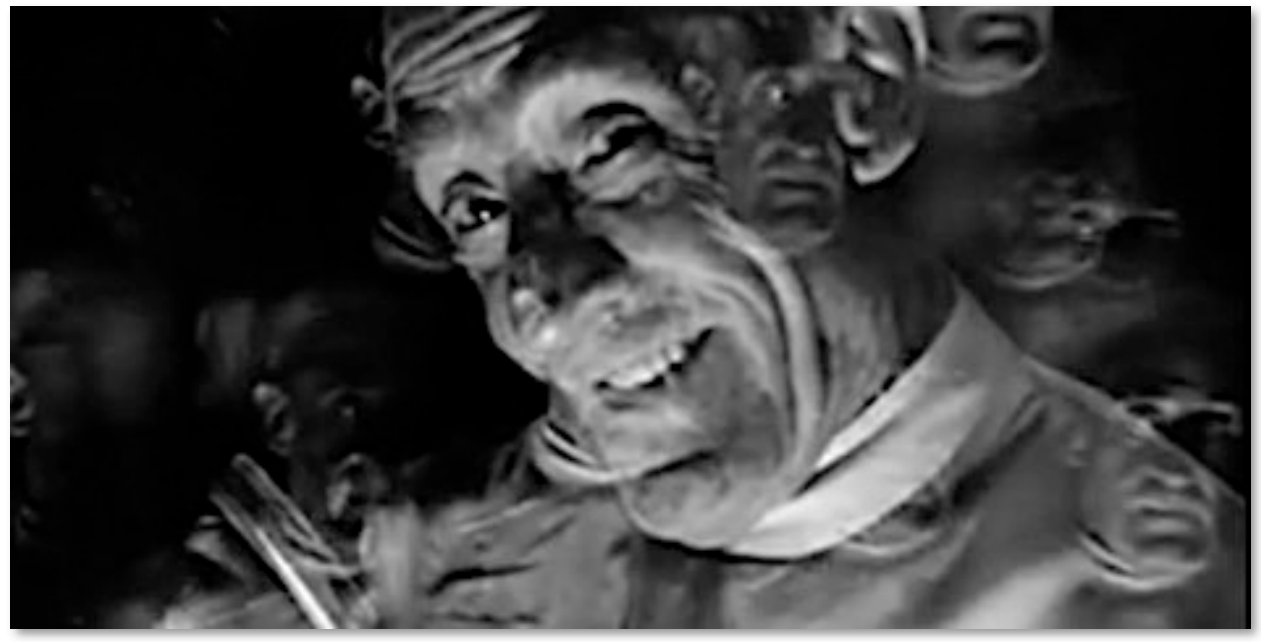

Figure 15. Image from Dark Passage (1947) [37].

The dream sequence is reminiscent of Anthony Kimmins's film Mine Own Executioner (1947) [47], released the same year, where a combination of hypnosis and drugs are used on a schizophrenic patient to help him recall repressed memories from his time as a prisoner of war. Within a ten-minute sequence, Adam Lucian (Kieron Moore) is portrayed through subjective camerawork as an air force pilot shot from the sky, captured behind enemy lines, carried to a prison and eventually tortured. This is until he finally turns the tables on his captors by becoming a killer (again portrayed subjectively), before making his escape.

Lucian's killer instinct and vulnerability are lucidly indicated through subjective camerawork, and when the hypnosis and drugs wear off, Lucian's memories are lost along with the hap-tech first-person imagery. Similarly, as Parry's nightmare, operation and victimisation concludes, so too 
does the subjectivity. The surgery in a way amputates us (the viewer) from the body vessel of Parry, who is no longer a condemned felon or a vulnerable botched surgery victim but is rather unveiled as the iconic and heroic figure of Bogart. This confident and leading man persona, with a face to match his righteous and innocent character, ejects the spectator from his body where we now watch him in a more conventional cinematic language (like Eaton's rough hero), rather than through him. Hap-tech narration has served its purpose, Parry is no longer presented in a negative light as killer or victim, and the remainder of the film is presented from a fictional position of strength, as Parry settles scores while meting out justice to those that have wronged him.

While Sobchack and many others have asserted that Lady in the Lake is defective as a camera-body experience, Dark Passage by contrast has been much better received. This I believe is owed not only to improvements in camera technology, but also because of the way such subjective camerawork is employed through hap-tech narration. Victim body camerawork is present in Montgomery's film during a few distinct moments but are too few and far between to be considered a hap-tech film. Additionally, the body vessel of Philip Marlowe (protagonist of Lady in the Lake) is a tough, confident, hardboiled detective who works within the confines of the law. This is in contrast to the weakened victim body or lawless killer body which makes up the criteria of hap-tech narration. In this way, Dark Passage and the body vessel of Parry can be considered the forge to which a majority of other subjective camera films and television programmes over time have emulated. I now qualify this by turning my attention towards two concise subjective case studies that portray hap-tech narration through the surrogate bodies of the killer and victim character.

\section{The Hap-Tech Body of the Killer}

The role of a killer body subjectively portrayed through first-person camerawork has been depicted in a vast selection of films across all genres. ${ }^{1}$ Of all the films mentioned below, Franck Khalfoun's Maniac (2012) [48], a remake of William Lustig's 1980 horror slasher film of the same name [49], provides one of the best examples of hap-tech narration because of both the form and content of the film, which at its crux explores the relationship between artificial and human bodies. Maniac is subjective from start to finish and tells the story of Frank Zito (Elijah Wood), a mentally disturbed man who collects and restores mannequins as both a job and a form of warped pleasure. Zito believes the mannequins to possess some form of life and helps to nurture this by murdering and scalping women. Returning the scalps to his workshop, Zito then arranges the hair from his victims upon each mannequin's head to breathe life into his collection of inanimate bodies.

The remake's use of subjective shots throughout its duration is perhaps influenced by the original's opening shot, in which Zito (Joe Spinell) looks through a beach telescope (Figure 16) at an unsuspecting couple before approaching and murdering them both. As Zito looks through the telescope, the viewer takes on his point-of-view, denoted by a binocular shot which blacks out the screen's edges, leaving a horizontal figure eight mise-en-scène (Figure 17).

The viewer hears Zito's grunts of excitement as he preys upon the pair of lovers before approaching and killing each of them. In Khalfoun's remake, the viewer is tethered to the camera in the film's entirety as the viewer/Zito selects targets through online dating websites, stalks women in public spaces and covertly watches them through private windows and slatted blinds. The film adopts hap-tech narration by utilising the uncomfortableness of the film's subjective camerawork to purport the viewer into Zito's skin.

1 Such titles include: Alfred Hitchcock's Psycho (1960), Steven Spielberg's Duel (1971), Jaws (1975), Dario Argento's Il Gatto A Nove Code (The Cat o'Nine Tails, 1971), Profondo rosso (Deep Red, 1975), John Carpenter's Halloween (1978), Irvin Kershner's Eyes of Laura Mars (1978), Sean S. Cunningham's Friday the 13th (1980), James Cameron's The Terminator (1984), John McTiernan's Predator (1987), Stanley Kubrick's Full Metal Jacket (1987), Jonathan Demme's The Silence of the Lambs (1991), Rémy Belvaux's Man Bites Dog (1992), Alex Proyas' The Crow (1994), Luc Besson's Léon: The Professional (1994), David Lynch's Lost Highway (1997), Sam Mendes' Road to Perdition (2002), Michael Haneke's Caché (Hidden, 2005), Jonathan Glazer's Under the Skin (2013) and Dan Gilroy's Nightcrawler (2014), to name just a few. 


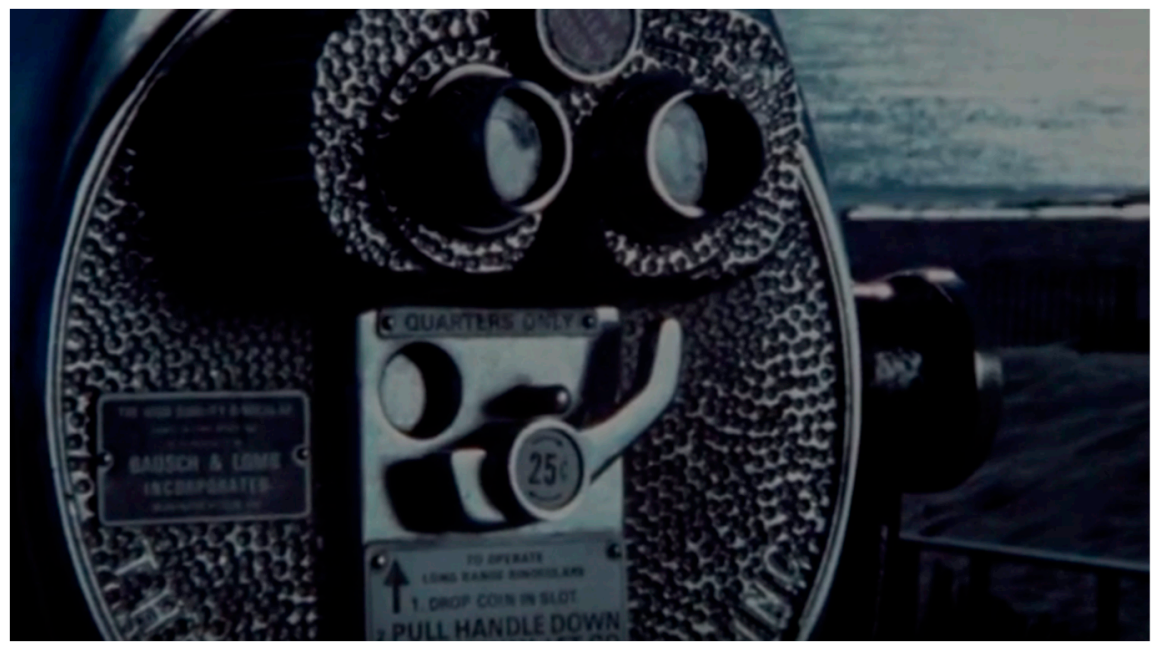

Figure 16. Image from Maniac (1980) [49].

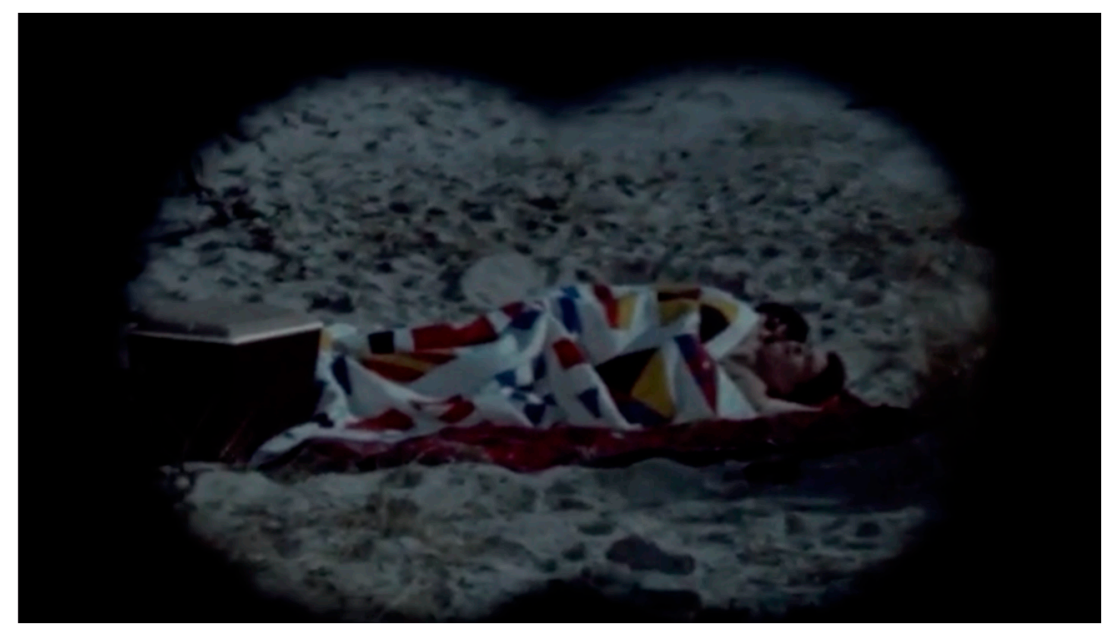

Figure 17. Image from Maniac (1980) [49].

A hap-tech narrative is produced in Maniac as the use of subjective camerawork (human and machine) feeds into a story about the clash between an organic body's conflict with a synthetic artifice. The use of technology in the film's production matches the onscreen story. Within the diegesis of Maniac, Zito perceives himself as a form of mannequin doll, which is explicitly indicated in two moments within the film. The first is during a dream sequence in which Zito studies his naked form within the mirror. As the camera moves down over his pelvis, a smooth plastic gloss replaces his genitals, temporally leaving him in a state somewhere between human and non-human. Later in the film, as he lies dying in his workshop after being stabbed with a metallic skeletal rod from a mannequin's hand, Zito visualises his collection of hair-covered mannequin victims coming alive and ripping away his skin. As they strip away flesh, organs and intestines, what is left underneath is a mannequin model of Zito, portraying his inhuman inner self (Figures 18 and 19). The viewer witnesses this from a privileged third-person perspective outside of Zito's body looking down. This is a trait established earlier in the film when Zito carries out a murder and is able to momentarily and euphorically escape the boundaries of his own skin and witness himself from above. 


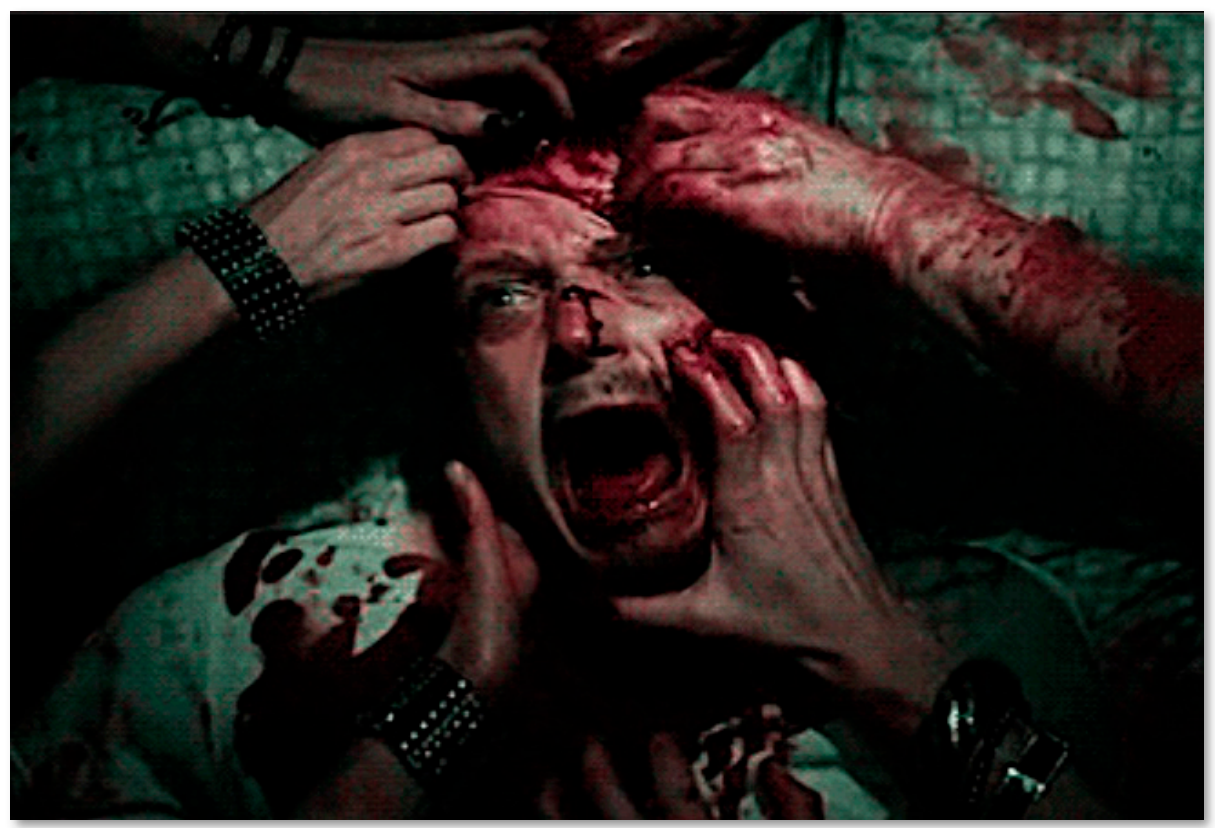

Figure 18. Image from Maniac (2012) [48].

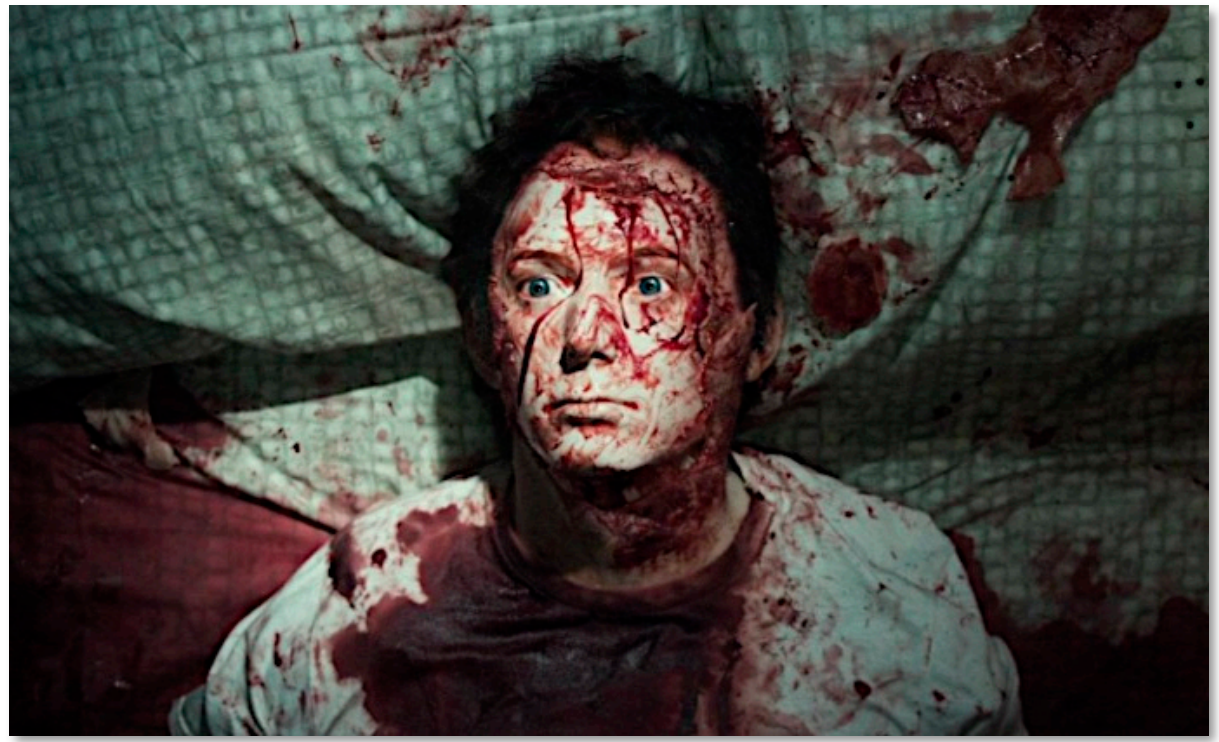

Figure 19. Image from Maniac (2012) [48].

Zito's synthetic self-perception is elucidated within the film's camerawork, which does not feel anchored by the gravity of a real body but, instead, has a type of weightlessness about it. Speaking about his role in the film, Wood has commented that, "what [the film's camerawork] lacks [... ] from some POV films [ ... ] is that sense of kinetic movement in lieu of a more graceful style" [50]. In a sense, his description is almost reminiscent of the mannequin dolls that the Zito character identifies with throughout the film: graceful yet kinetically defunct. This fictional contention is emphasised through the technology of Maniac, which is shot digitally on a Red Epic brand camera [51], giving the subjectivity an all too clean gloss that appears more vivid than what the natural eye would see. Following D.N. Rodowick's [52] thoughts on digital film as a replacement to celluloid, the digital sight through Zito's character (and the Red Epic camera) can be considered a loss of an indexical transference of reality.

Rodowick [52] (p. 170) argues that the inauguration of digital cinema has bought with it a change in which "physical reality gives way to the composition of 'elastic' reality". This is because "profilmic 
space has been pulled into the universe of numbers" [52]. He elaborates, stating that "[d]igital processes are increasingly used actually to efface and, in some cases, entirely to rewrite the actor's body. Film 'actors' have become Frankenstein hybrids: part human, part synthetic" [52] (p. 6). Although Rodowick here is referring in particular to postproduction special effects, such as morphing bodies in sci-fi fantasy films, his concepts still resonate with that of the off-screen body of Zito. The digital camera-body gives the screen world a particular aesthetic sheen that falls between real and artifice, which within the story is exactly what Zito struggles to differentiate. Every kill Zito makes removes him further from humanity until all that is left is a lifeless model. His confused anxious state is often qualified through the use of reflections within the film. This is emphasised during a moment in which Zito approaches a shop window displaying several CCTV monitors (Figure 20). Here, his image is exploded across the entirety of these screens which stresses his multiple and synthetic sense, while widening the chasm between the character and the spectator's ability to identify with him.

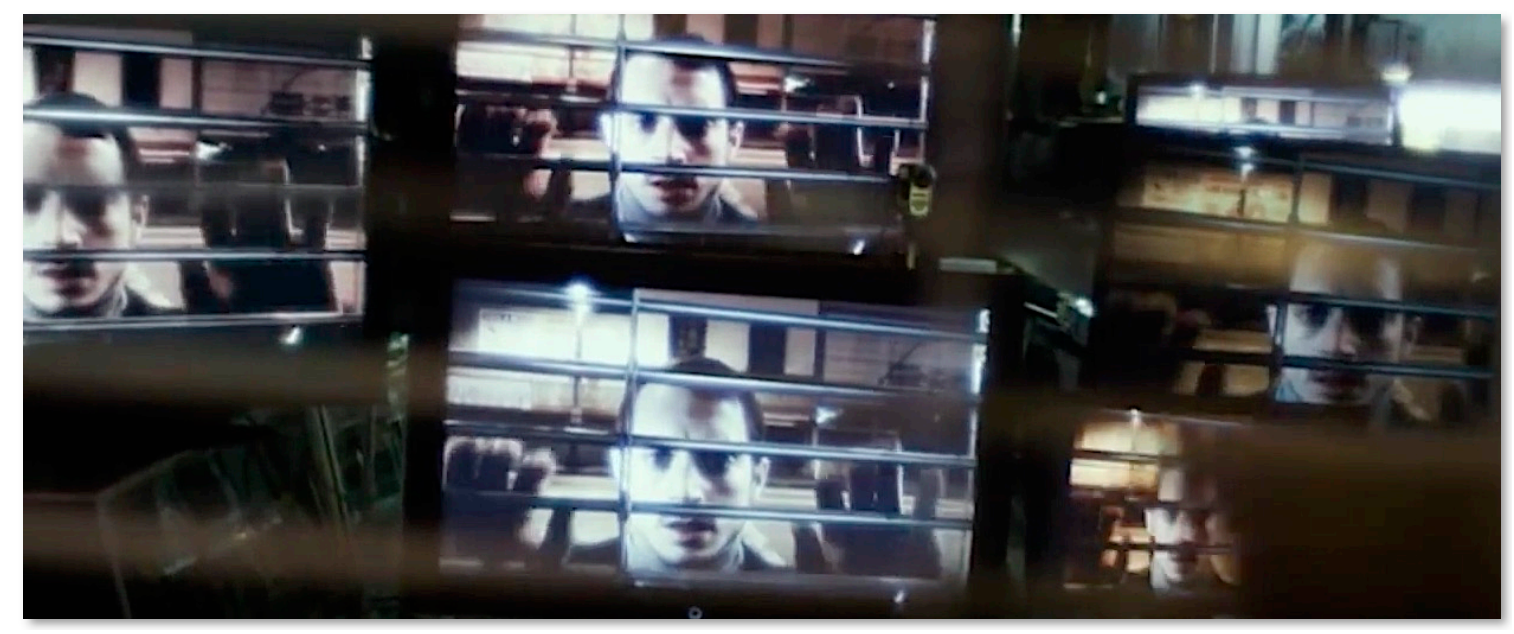

Figure 20. Image from Maniac (2012) [48].

It is through these allusions to split personality and paranoia that Zito's killer instinct is balanced by a victim persona, similar to Lewis in Peeping Tom or subjective Parry from Dark Passage. Zito frequently experiences severe headaches, which are extended to the viewer through wavy askew camera angles, blurry frame edges and a piercing high-pitch frequency sound. All of this works together to paint Zito as someone who is suffering both physically and mentally. His pain serves as a way to explain and offset some of his actions as a killer through hap-tech narration, where victim and killer are merged into one.

\section{The Hap-Tech Body of the Victim}

Similar to the killer body, the subjective use of a hap-tech victim body can be seen in a range of subjective titles. Gaspar Noé's Enter the Void (2009) [53] is one example which portrays the journey from physical assault to death in the first half hour of the film's runtime. Set in Tokyo and seen through the eyes of a young protagonist drug dealer named Oscar (Nathaniel Brown), the film makes use of strict subjective camerawork to portray the inhabitation of Oscar's surrogate body as he walks the streets of a city, high on dimethyltryptamine (DMT) with a friend, Victor (Olly Alexander), before being gunned down in the washroom of a bar. The subjectivity is conveyed through an Arricam Lite (LT), which is a small lightweight camera that can be mounted onto a photographer's shoulder, which in Noé's film is used to convey the sense of inhabiting Oscar's body. The compactness of the camera makes the movement look natural and familiar, which is reinforced through continuous action and an unbroken shot. Few of Oscar's manoeuvres feel contrived and instead seemingly appear in real-time. The authenticity of Oscar's corporeal surrogate is detailed with continuous intermittent blackouts to represent blinking. 
The temporality of the blinking detail, however, is somewhat jarring as it is not in synchronisation with the viewer's own blinking eyes and, therefore, becomes noticeable and awkward. Human perception for the most part does not notice its own blinking habits, so to become visually aware of this onscreen can feel strange for the viewer. Such artifice again impairs the human body vessel, ushering in preliminary moments of awkwardness and uneasy viewing. These minor moments of corporeal discomfort foreshadow Oscar's own death when he reaches his final destination, a trap in the form of a drug sting, and is shot through the bathroom door. As viewer/Oscar slump to our knees, we study the blood on our hands (Figure 21). The mise-en-scène then rises from our body, ghostlike, to become an incorporeal spirit that spends the remainder of the film drifting across the neon colours of the city and the people that inhabit it, like an apparitional vapour.

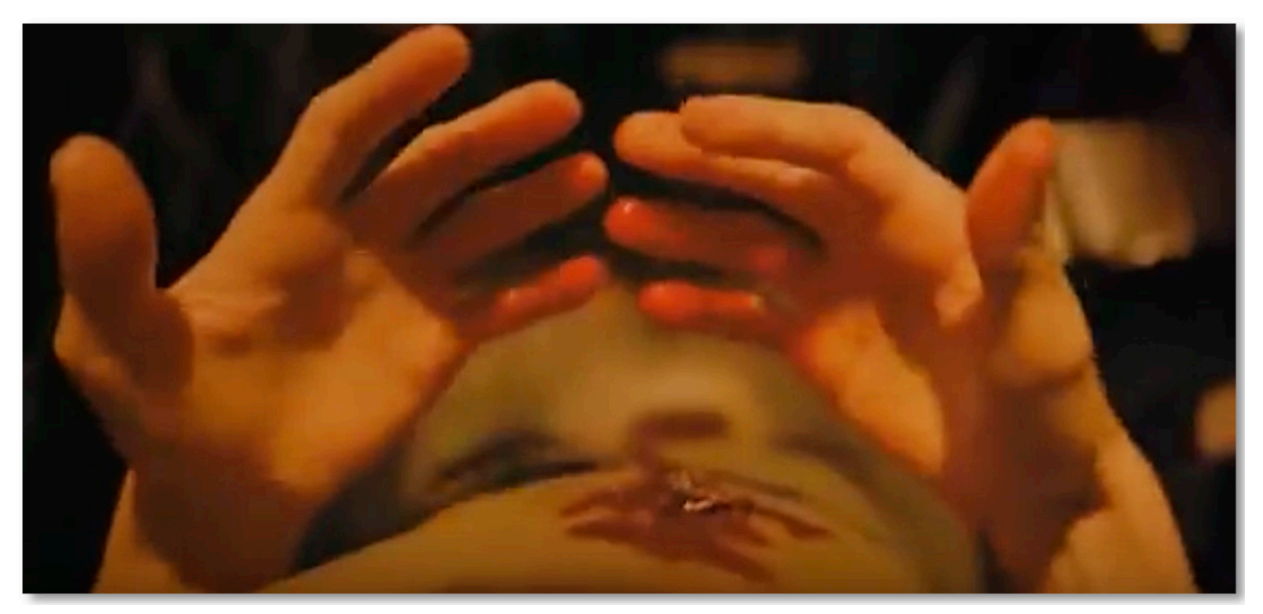

Figure 21. Image from Enter the Void (2009) [53].

In William Brown and David H. Fleming's paper [54], 'Voiding Cinema: Subjectivity Beside Itself or Unbecoming Cinema in Enter the Void', the authors consider this stylistic shift in the film as a significant factor in transporting the viewer into the void of death. They assert that the film "segues together in [ ... ] unbroken continuity three distinct and fluctuating modalities of cinematic narration, which [they] respectively describe as first-person, second-person and 'absent'" [54] (p. 127). As they state, the early POV "takes up an embodied position synonymous with Oscar's eyes and brain, positioning the viewer behind his eyelids and within his subjective consciousness" [54] (p. 128). The second mode takes place after Oscar is shot in which the viewers are shown "a series of 'disembodied' perception images" [54] as the protagonist transcends his own body in what the authors call "a second person perspective" [54]. In this mode, "images from Oscar's infanthood, childhood, adolescence and adulthood are folded together and stylistically linked by a framing trope wherein the camera is strategically positioned behind Oscar's body, holding the back of his head in medium close-up" [54]. This idea of second-person perspective is a departure from the embodied POV. The authors clearly highlight that this idea of a second-person perspective is not an all-encompassing term to be used anytime in which the back of someone's head is portrayed onscreen. Instead, it serves as a way "to introduce a gap or fissure between Oscar as the subject and object of the gaze, between Oscar as subject and object" [54]. It leads them into discussing how Oscar relinquishes his ego to "become beside oneself" [54] before eventually becoming "absent, or voided, from the film" [54]. As Brown and Fleming note, "Oscar's 'disappearance' from the film is not marked by a formal stylistic device like the cut, which usually separates different POV shots from objective shots and so on. Instead, without a cut, Oscar has drifted into 'the void'" [54] (p. 129). This is verified by the absence of blinking eyes and corporeal movement, replaced with "free-form" movement [54] (p. 130).

As Brown and Fleming further note, "Enter the Void is purportedly inspired by the Tibetan Book of the Dead" [54] (p. 135), a text that Oscar and Victor discuss en route to the bar. As Brown and Fleming highlight, the text "seek[s] to promote the loss of ego" [54], a notion that is foreshadowed before Oscar 
reaches his final destination and the POV camerawork transcends into second person then void as "the boundary between subject and object disappears (and [ ... ] the void appears)" [54]. This transcendence or loss of ego as the body disappears into the void is what renders hap-tech narration as Oscar's body, illustrated through the POV camerawork, is dispensed with, turning him into a victim.

Further application of victimisation, death and ambiguous states of subjectivity through camerawork has become a ubiquitous trope in the found footage genre, in which the camera plays a diegetic role. In particular, this was marked by The Blair Witch Project (Eduardo Sánchez and Daniel Myrick, 1999) [55], in which the abrupt blackout at the end of the film signifies a character's death. A decade prior to The Blair Witch Project, a similar use of pseudo-documentary and black screen is used to show a similar portrayal of death in Patrick Sheane Duncan's subjective Vietnam War film, 84C MoPic (1989) [56].

The entwinement of death, the camera and the photograph is a well-established area of research that has been robustly scrutinised in the past through authors that includes André Bazin's [57] "The Ontology of the Photographic Image", Roland Barthes's [58] Camera Lucida: Reflections on Photography, Raymond Bellour's [59] "The Pensive Spectator: Disparate Processes Used in Viewing Cinema and Photography" and Laura Mulvey's [60] Death 24x a Second: Stillness and the Moving Image, amongst others. There are different variations within each, but the main premise is fundamentally that cameras and photographic stillness is reciprocal with the concept of death. This is because the essence of photography is the arrestment of time and movement. In Camera Lucida, Barthes refers to photographers as "agents of death" [58] (p. 92) who, with fingers on triggers, possess the technological ability to extract duration. As Barthes asserts, "Death is the eidos of [a] Photograph" [58] (p. 15).

Adapting this line of argument, with focus away from the photograph and upon the camera apparatus, we can consider how the diegetic inclusion of the mobile camera in the found footage genre plays a large part in transporting a body of the living over to the dead, as is the conventional trope in most uses of this cinematic style. The protagonists from The Blair Witch Project and 84C MoPic are understood by viewers to both be killed within their respective diegetic worlds, denoted by the void of the black screen, the nothingness, as the characters and spectators are abruptly subtracted from the fiction of the film and the movements from the bodies that carry the camera. The found footage genre, thus, puts the extension and limitation of the subjective camera into two extreme poles of life and death. ${ }^{2}$

Sandwiched between these two extremities of life and death, the content of these film styles is characterised by unsteady, spasmodic camerawork. These rough segments of footage are often portrayed to give the viewer a sense of authenticity and involvement in the raw docudrama process, which will frequently involve the camera in transition and down to the side of a character, recording unbeknown to them as they move. Footage like this is generally portrayed through an irregular and chaotic mise-en-scène where such imagery has reportedly caused viewers to experience motion sickness. ${ }^{3}$ If the subjective camera as a surrogate body represents life, and blackness or stillness a form of death, then spasmodic camerawork and irregular angles (from a subjective disposition) can be considered a form of diegetic illness, in line with the actuality of the motion sickness affect.

This is what Julian Schnabel's Le Scaphandre et le Papillon (The Diving Bell and Butterfly) puts into practice, to present a hap-tech experience of a victim character through the surrogate vessel of the ill, weakened and damaged body. The film gruellingly charts the biographic first-person experiences of Jean-Dominique Bauby (Mathieu Amalric), a renowned author and editor for a fashion publication who became inflicted with locked-in syndrome (LIS) after suffering a severe stroke. Before passing

2 This pattern can be seen in numerous found footage films including: Ruggero Deodato's Cannibal Holocaust (1980), Jaume Balagueró's Rec (2007) and Rec 2 (2009), Matt Reeves' Cloverfield (2008), Oren Peli's Paranormal Activity (2007) and Barry Levinson's The Bay (2012).

3 The initial box office opening of The Blair Witch Project had numerous complaints that the camera movement was making viewers feel nauseous. One cinema in particular reported that within one month, this was happening at an average of at least one person per showing. Further details at: The Washington Post, Emily Wax, "The Dizzy Spell of Blair Witch Project" at http://www.washingtonpost.com/wp-srv/style/movies/features/witchdizzy.htm (accessed 19 June 2019). 
away, Bauby spent a little over fifteen months trapped within the confines of his own body, only able to move and control his left eye, which would become his entire spectrum of communication. The chaotic feel of this film with erratic camera movement bears similarity to the found footage films mentioned above. But because the camera does not play a diegetic part in the story of the film, subjective death by way of the camera is avoided. Instead, the film subjectively focuses on a corporeal space between life and death in the form of illness.

With a sense of irony, the camera equipment employed to represent these subjective moments of a physically redundant body consist of an Arriflex 435 Super Speed camera and an Arri Tilt Shift lens. This equipment, which is both light and mobile with a wide range of spherical movement, is used within the film to represent Bauby's left eye as he frenetically scans his environment to have some sense of his world. As characters enter the mise-en-scène to address the viewer/Bauby, they appear at an askew angle to match up with the way Bauby perceives them either from his lopsided position in bed or with his head drooping to one side when sat up.

The most adverse use of victim experience within the film is a distressing scene in which a neurologist informs Bauby that his right eye must be occluded to prevent from turning septic. Tethered to his gaze, the viewer undergoes this surgery too, watching out of the bad eye as the lid is pulled down and stitched closed (Figures 22-24).

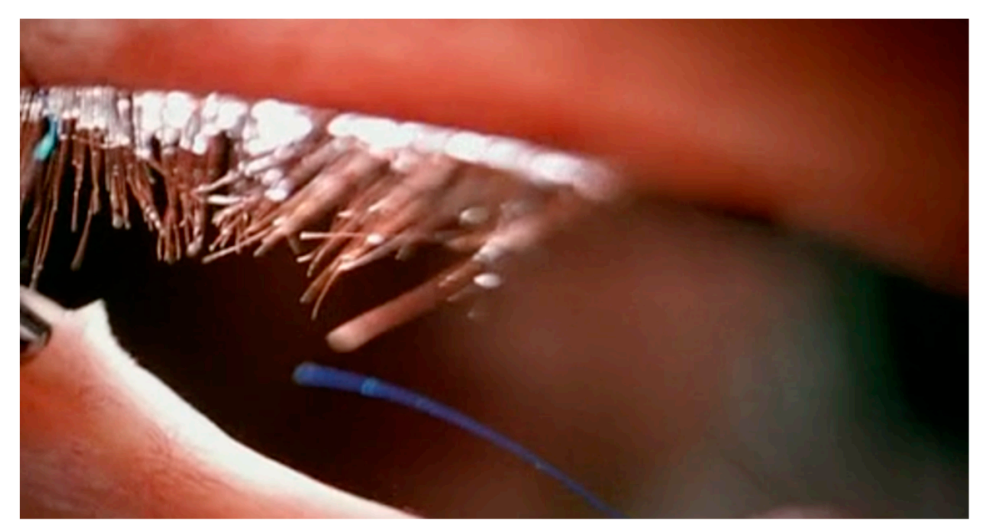

Figure 22. Image from The Diving Bell and Butterfly (2007) [34].

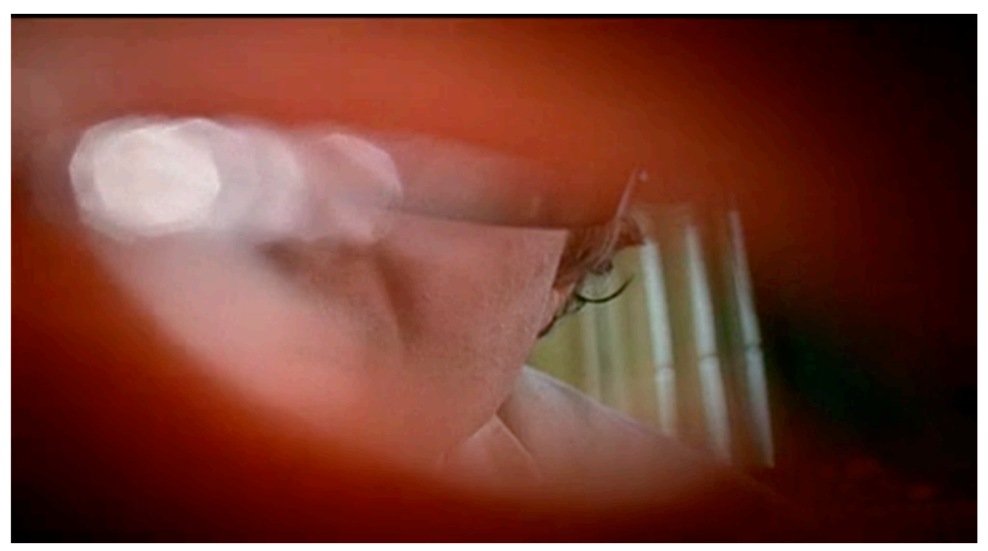

Figure 23. Image from The Diving Bell and Butterfly (2007) [34]. 


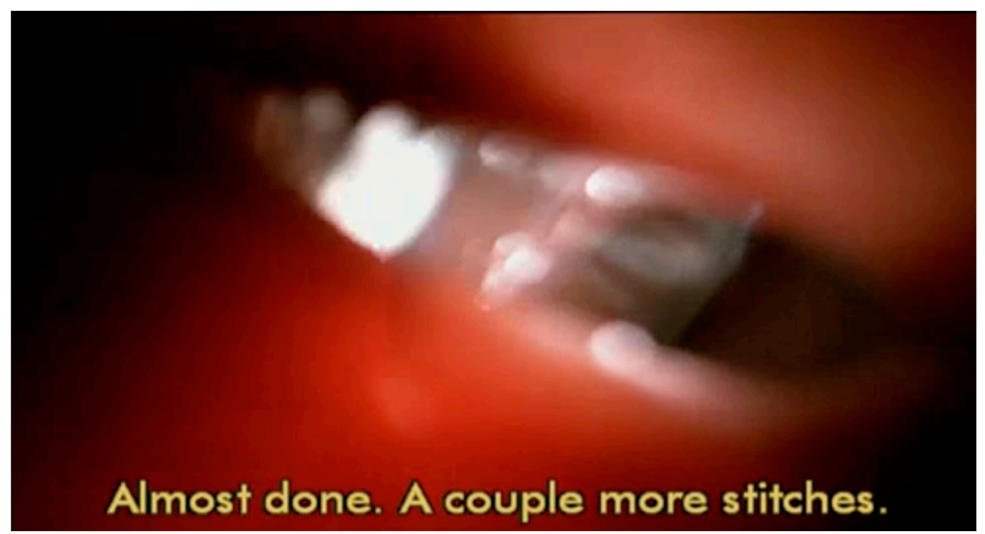

Figure 24. Image from The Diving Bell and Butterfly (2007) [34].

The effect is achieved by way of a pink latex oval shaped eyehole that covers the camera lens, which the surgeon proceeds to sew up. Watching this experience through a sloped pinkish oval as the needle pushes through flesh, suturing the eye shut is as lengthy as it is disturbing, with each stitch painfully felt by the viewer.

With the right eye out of action, Bauby is left to interact with the world through his left eye as it becomes a communication channel through a system of structured blinking: once for "yes", twice for "no", which later develops to include a letter chart where characters are selected through this blinking pattern. This process begins painstakingly slow and Bauby complains through thought tracking about the pace and difficulty he has in keeping his eye wide open in anticipation for the letter.

The crude technology of the letter chart, like the subjective camera, simultaneously limits and extends Bauby. It enslaves and dehumanises him through the way in which he is unable to choose when he can speak. Instead, he can only respond when someone else, holding the lettered technology, initiates a conversation with him. On the other hand, Bauby is extended through this technology back into the world of communication and is able to articulate his inner thoughts through his own voice, albeit with a degree of compromise as the words are read back to him by way of an external speaker. As Bauby emerges from the darkness of his own thoughts back into a communicative existence, where speech becomes faster through practice and transparency of the lettered chart, the first-person camerawork recedes in place of a third-person cinematic syntax. Here, freedom through memories and dream sequences denote the viewer's own escape from the corporeal prison. Similar to Dark Passage, the body of the triumphant overthrows the body of the victim as Bauby sets about to write his biography through his complex body phraseology.

\section{Conclusions}

In this paper, I formulated the concept of hap-tech narration through Ihde's postphenomenological framework of human-technology relationships, particularly embodiment which simultaneously extends and limits a user through a tool. I discussed how the noesis of the camera is something that viewers embody to enter the cinematic space and how we are simultaneously cut off from it, in a hermeneutical capacity (another of Ihde's human-technology relationships) by the frame of the cinema screen. Subjectivity, as I argued, is thus a confused and often uncomfortable space through the way in which the viewer experiences friction between embodiment and hermeneutic relations. Consequentially, this paper has offered rationale as to why subjective cinema (as highlighted by Galloway) is a negative experience. Subsequently, I argued that this negative experience is primarily adopted for the surrogacy of killer or victim characters, enabling the viewer to feel the discomfort through the surrogate's skin.

Further development of the hap-tech victim body could be continued over to a subset of social ineptness when we consider subjective moments from socially awkward characters in cinema. For example, Benjamin Braddock's (Dustin Hoffman) subjective scuba diving pool scenes in Mike 
Nichols's The Graduate (1967) [61], the unsocial non-conformist Ricky Fitts (Wes Bentley) who isolates himself from behind the lens of his mobile camcorder in Sam Mendes's American Beauty (1999) [62], or the school-bullied Andrew Detmer (Dane DeHaan), who progresses to supernatural killer in Josh Trank's pseudo-documentary, camera diary film Chronicle (2012) [63].

Within these titles and others discussed throughout this paper, the camera as an extending and limiting technological apparatus enables the viewer to step into a surrogate body vessel and experience some of the negative connotations of a character within their world. This is primarily due to the character's isolation and inability to control their self, either morally, physically or socially in a conventional diegetic setting. This lack of control within the narrative world mirrors a lack of control between the seated viewer and cinema screen. Just as the viewer is powerless to change the next frame of action, good hap-tech narration similarly deploys a sense of powerlessness within the narrative in order to convincingly extend viewers into a subjective, awkward experience of corporeality.

Of course, there are experimental subjective films which seemingly fall outside the rules of hap-tech narration, Alexsandr Sokurov's Russian Ark (2002) [64], for example, which is renowned for its unbroken continuous shot of $96 \mathrm{~min}$, is a rich experimentation that plays with the duration of the subjective shot at a time in which digital cinema was beginning to rival celluloid. As such, the film feels as if it strives to be more innovative than story focused, rather like a modern attraction in Tom Gunning's sense of the term. The character that the viewer inhabits feels mysterious and ghostlike, strengthened by their invisibility to the majority of other characters (as well as the viewer). It is implied that this mysterious surrogate vessel that the viewer perceives events through is indeed a character that has died under horrific circumstances; thus, an element of victimisation and violence can be linked to hap-tech narration through this avant-garde film, albeit in a loose way.

As this paper has illustrated, there is a strong link between the subjective POV and violence which is what FPS games are founded upon. Further investigation into this might uncover that subjectivity through new media (within a capitalist society) could similarly be read as a form of violence that reinforces the ego through solipsism which to some extend kills unmediated togetherness. Sherry Turkle's [65] book, Alone Together: Why We Expect More from Technology and Less from Each Other, is one such example that has already gone some way to consider this. Thus, the subjective and assaultive outlook of POV, illustrated in hap-tech narration, could translate to the subjective, assaultive and solipsistic technology of social media, which much of Western Civilization is impelled to look through. If this is the case, then hap-tech narration could potentially serve as more than just a tool to investigate the subjective outlook of a fictional onscreen character but could also become a framework to consider the real-world outlook of our digital selves.

Funding: This research received no external funding.

Conflicts of Interest: The author declares no conflict of interest.

\section{References}

1. Sobchack, V. The Address of the Eye: A Phenomenology of Film Experience; Princeton University Press: Princeton, NJ, USA, 1992.

2. Shaviro, S. The Cinematic Body; University of Minnesota: Minneapolis, MI, USA, 1993.

3. Marks, L. The Skin of the Film: Intercultural Cinema, Embodiment, and the Senses; Duke University Press: Durham, NC, USA, 2000.

4. Barker, J. The Tactile Eye: Touch and the Cinematic Experience; University of California Press: Berkeley, CA, USA, 2009.

5. Galloway, A. Gaming: Essays on Algorithmic Culture; University of Minnesota Press: Minneapolis, MI, USA, 2006.

6. Hitchcock, A. Spellbound; United Artists: West Hollywood, CA, USA, 1945.

7. Montgomery, R. Lady in the Lake I; Metro-Goldwyn-Mayer: Beverly Hills, CA, USA, 1947.

8. Demme, J. The Silence of the Lambs; Orion Pictures: Los Angeles, CA, USA, 1991.

9. Metz, C. Impersonal Enunciation, or the Place of Film; Columbia University Press: New York, NY, USA, 2015. 
10. Sorfa, D. Seeing oneself speak: Speech and thought in first-person cinema. Jomec J. 2019, 13, $104-121$. [CrossRef]

11. Sobchack, V. Carnal Thoughts: Embodiment and Moving Image Culture; University of California Press: Berkeley, CA, USA, 2004; p. 67.

12. Merleau-Ponty, M. Phenomenology of Perception; Routledge: Abingdon, UK, 2002.

13. Ihde, D. Postphenomenology and Technoscience: The Peking University Lectures; University of New York Press: New York, NY, USA, 2009; p. 23.

14. Ihde, D. Bodies in Technology; University of Minnesota: Minneapolis, MI, USA, 2002.

15. Husserl, E. Ideas: General Introduction to Pure Phenomenology; Routledge Classics: London, UK, 2012.

16. Ihde, D. Technics and Praxis; Springer Netherlands: Dordrecht, The Netherlands, 1979.

17. Ihde, D. Technology and the Lifeworld: From Garden to Earth; Indiana Press: Bloomington, IN, USA, 1990; pp. 72-108.

18. Heidegger, M. Being and Time; London S.C.M. Press: London, UK, 1962.

19. Ihde, D. Existential Technics; State University of New York Press: New York, NY, USA, 1983.

20. Cameron, J. The Terminator; Orion Pictures: Los Angeles, CA, USA, 1984.

21. Cameron, J.; Dunham, J. James Cameron: Interviews; University Press of Mississippi: Jackson, MI, USA, 2012; p. 17.

22. Bigelow, K. Strange Days; 20th Century Fox: Los Angeles, CA, USA, 1995.

23. Shaviro, S. Regimes of vision. Kathryn Bigelow. Strange days. Polygraph 2001, 13, 59-68.

24. Jonze, S. Being John Malkovich; USA Films: New York, NY, USA, 1999.

25. Powell, M. Peeping Tom; Anglo-Amalgamated Film Distributors: London, UK, 1960.

26. Bordwell, D. Camera movement and cinematic space' ciné-tracks. J. Film Commun. Cult. Polit. 1977, 1, 2.

27. Branigan, E. Narrative Comprehension and Film; Taylor \& Francis: Oxfordshire, UK, 2013; p. 157.

28. Eaton, A.W. Robust immoralism. J. Aesthet. Art Crit. 2012, 70, 281-292. [CrossRef]

29. Chase, D. The Sopranos; HBO: New York, NY, USA, 1999-2007.

30. Carroll, N. Rough heroes: A response to A. W. Eaton. J. Aesthet. Art Crit. 2013, 71, 2013. [CrossRef]

31. Brown, T. Breaking the Fourth Wall: Direct Address in Cinema; Edinburgh University Press: Edinburgh, UK, 2013.

32. Branigan, E. Point of View in the Cinema: A Theory of Narration and Subjectivity in Classical Film; Mouton de Gruyter: Berlin, Geramny, 1984.

33. Wilson, G.M. Narration in Light: Studies in Cinematic Point of View; Johns Hopkins University Press: Baltimore, MD, USA, 1986; p. 86.

34. Schnabel, J. Le Scaphandre et le Papillon (The Diving Bell and Butterfly); Pathé and Miramax Films: Paris, France; Los Angeles, CA, USA, 2007.

35. Verhoeven, P. Robocop; Orion Pictures: Los Angeles, CA, USA, 1987.

36. Scorsese, M. Taxi Driver; Columbia: Los Angeles, CA, USA, 1976.

37. Daves, D. Dark Passage; Warner Bros: Burbank, CA, USA, 1947.

38. Eastwood, C. American Sniper; Warner Bros: Burbank, CA, USA, 2014.

39. Naishuller, I. Hardcore Henry; STX Entertainment: Burbank, CA, USA, 2015.

40. Virilio, P. War and Cinema: The Logistics of Perception; Verso: New York, NY, USA, 1989.

41. Kittler, F.A. Gramophone, Film, Typewriter; Writing Science, Stanford, Calif.; Stanford University Press: Palo Alto, CA, USA, 1999.

42. Garwood, I. The Sense of Film Narration; Edinburgh University Press: Edinburgh, UK, 2013.

43. Lasseter, J. Toy Story 2; Walt Disney Pictures and Pixar Animation Studios: Orlando, FL, USA, 1999.

44. Sheets, J.M. The Primacy of Movement; John Benjamins Publishing Company: Amsterdam, The Netherlands, 2011.

45. Pope, N. Chronicle of a Camera: The Arriflex 35 in North. America; University Press of Mississippi: Jackson, MI, USA, 2013; p. 17.

46. Enticknap, L. Moving Image Technology: From Zoetrope to Digital; Wallflower: London, UK, 2005; p. 38.

47. Kimmins, A. Mine Own Executioner; British Lion Films: London, UK, 1947.

48. Khalfoun, F. Maniac; IFC Midnight: New York, NY, USA, 2012.

49. Lustig, W. Maniac; Magnum Motion Pictures Inc: Washington, DC, USA, 1980.

50. Wood, E. Maniac Interview. Available online: https://www.youtube.com/watch?v=v-U1trIqLh0 (accessed on 11 June 2019). 
51. Shot on What, Maniac. Available online: https://shotonwhat.com/maniac-2012 (accessed on 11 June 2019).

52. Rodowick, D.N. The Virtual Life of Film; Harvard University Press: Cambridge MA, USA, 2007.

53. Noé, G. Enter. the Void; Wild Bunch Distribution: Berlin, Germany, 2009.

54. Brown, W.; Fleming, D.H. Voiding cinema: Subjectivity beside itself or unbecoming cinema in enter. the void. Film Philos. 2015, 19, 124-145. [CrossRef]

55. Myrick, D.; Sánchez, E. The Blair Witch Project; Artisan Entertainment: Santa Monica, CA, USA, 1999.

56. Duncan, P.S. 84C MoPic; New Century Vista Film Company: Los Angeles, CA, USA, 1989.

57. Bazin, A. The ontology of the photographic image. Film Q. 1960, 13. [CrossRef]

58. Barthes, R. Howard, R. Camera Lucida: Reflections on Photography; Vintage: New York, NY, USA, 1993.

59. Bellour, R. The pensive spectator-disparate processes used in viewing cinema and photography. Wide Angle A Q. J. Film Hist. Theory Crit. Pract. 1987, 9, 6-10.

60. Mulvey, L. Death $24 x$ a Second: Stillness and the Moving Image; Reaktion Books: London, UK, 2006.

61. Nichols, M. The Graduate; AVCO Embassy Pictures and United Artists: Los Angeles, CA, USA, 1967.

62. Mendes, S. American Beauty; DreamWorks Pictures: Los Angeles CA, USA, 1999.

63. Trank, J. Chronicle; 20th Century Fox: Los Angeles, CA, USA, 2012.

64. Sokurov, A. Russian Ark; Wellspring Media: New York, NY, USA, 2002.

65. Turkle, S. Alone Together: Why We Expect. More from Technology and Less from Each Other; Basic Books: New York, NY, USA, 2011.

(C) 2019 by the author. Licensee MDPI, Basel, Switzerland. This article is an open access article distributed under the terms and conditions of the Creative Commons Attribution (CC BY) license (http://creativecommons.org/licenses/by/4.0/). 